\title{
Polymers Decorated with Functional Motifs for Mitigation of Steel Corrosion: An Overview
}

\author{
N. A. Aljeaban, ${ }^{1}$ L. K. M. O. Goni, ${ }^{2}$ B. G. Alharbi, ${ }^{1}$ M. A. Jafar Mazumder $\mathbb{D}^{2},{ }^{2}$ S. A. Ali, ${ }^{2}$ \\ T. Chen, ${ }^{1}$ M. A. Quraishi, ${ }^{3}$ and H. A. Al-Muallem ${ }^{2}$ \\ ${ }^{1}$ EXPEC ARC, Saudi Aramco, Dhahran 31311, Saudi Arabia \\ ${ }^{2}$ Chemistry Department, King Fahd University of Petroleum \& Minerals, Dhahran 31261, Saudi Arabia \\ ${ }^{3}$ Center of Excellence in Corrosion, King Fahd University of Petroleum \& Minerals, Dhahran 31261, Saudi Arabia
}

Correspondence should be addressed to M. A. Jafar Mazumder; jafar@kfupm.edu.sa

Received 3 December 2019; Revised 4 March 2020; Accepted 13 March 2020; Published 1 April 2020

Academic Editor: Jan-Chan Huang

Copyright (C) 2020 N. A. Aljeaban et al. This is an open access article distributed under the Creative Commons Attribution License, which permits unrestricted use, distribution, and reproduction in any medium, provided the original work is properly cited.

Corrosion is a hazardous phenomenon having a devastating impact on technological and industrial applications, particularly in the oil and gas industries. Therefore, controlling the corrosion of metals is an important activity of technical, economical, environmental, and aesthetical importance in order to save huge expenses in materials, equipment, and structure. The use of corrosion inhibitors is one of the best options for controlling the metallic corrosion in various corrosive media. Numerous problems aroused with the use of inorganic and small molecule organic corrosion inhibitors, and the use of polymeric corrosion inhibitors came into limelight. This review article provides an overview of the recent development of different classes of corrosion inhibitors with special emphasis on different functional motifs of natural, synthetically modified natural, and synthetic polymeric materials. The significance, mechanism, and challenges of using polymeric materials as corrosion inhibitors are also highlighted in the review.

\section{Significance of Corrosion}

Corrosion is referred to as the deterioration of the materials by the chemical reactions between materials and their reactive ambiance [1]. It is a hazardous phenomenon having a devastating impact on gas and oil manufacture and their subsequent transportation, triggered more or less by almost any aqueous environment and happens by means of redox reactions in gas and oil production, handling, and pipeline systems [2]. Technically, corrosion is considered a bounded electrochemical reduction-oxidation (redox) reaction taking place on the surface of materials, typically metals, prompting the release of electrons by the dissolution of metal and their successive transfer to another position on the surface causing the oxygenated water or hydrogen ions to be reduced and resulting in gradual deterioration and consequent failure of the host material. This corrosion process consists of a cathode, an anode, and an electrolyte. The anode is the location where the corrosion of metals takes place to generate free electrons, which travel through the corrosive electrolytic medium to the cathode, where hydrogen ions (from an acidic corrodant) are reduced to hydrogen gas. Natural gas and crude oil usually contain several highly contaminated products, which are innately corrosive. Free water, carbon dioxide $\left(\mathrm{CO}_{2}\right)$, and hydrogen sulfide $\left(\mathrm{H}_{2} \mathrm{~S}\right)$ are well-established examples of extremely corrosive media in case of oil and gas wells and pipelines. Furthermore, oxygen contaminations in basic or neutral conditions lead to the production of hydroxyl ions through the reduction of oxygenated water by the current produced at the anodic site due to the oxidation process [3]. In general, upon exposure to metals, the chemical species, such as moisture/water $\left(\mathrm{H}_{2} \mathrm{O}\right)$, acids $\left(\mathrm{HNO}_{3}, \mathrm{HCl}\right.$, and $\left.\mathrm{H}_{2} \mathrm{SO}_{4}\right)$, bases $\left(\mathrm{NaHCO}_{3}, \mathrm{CaCO}_{3}\right.$, and $\left.\mathrm{NaOH}\right)$, table salts $(\mathrm{NaCl})$, aggressive metal polishes, and gases (ammonia, formaldehyde, and sulfur-containing gases and liquid chemicals), perpetuate the degradation of the metals [4].

Corrosion is a huge concern for most of the industrialized countries. Even thoguh oil companies around the world 
spend a lot of money on tackling corrosion, casualties, economic losses, and environmental side effects still take place [5]. It has been reported that the maintenance cost of the corrosion-related issues in industries/establishments for any country is in the range of $1-5 \%$ of its gross national product (GNP) [6]. A study revealed by the National Association of Corrosion Engineers (NACE) in 2013 has shown that the global cost of corrosion was estimated to be US $\$ 2.5$ trillion, which was equivalent to $3.4 \%$ of the global gross domestic product (GDP) of that year [7]. The total cost of corrosion in the Gulf Cooperation Council (GCC) states was estimated to be US\$57.96 billion in 2011 [8]. Among the GCC states, the Kingdom of Saudi Arabia incurred the highest annual cost of corrosion. The United Kingdom suffered a corrosion cost of $£ 13.65$ billion in 1969 [9]. Corrosion has a severe impact on between a quarter and a half of all drinkable water primarily in France, particularly old ones that are made of cast iron or uncoated steel [5].

Since corrosion causes loss of economic, natural resources, and human lives in case of infrastructure collapses, it is of paramount importance to look into smart and developed corrosion mitigation techniques. Anodic protection [10], cathodic protection [11, 12], coating [13], and alloying are some of the approaches towards mitigating corrosion. Exploitation of chemical inhibitors $[14,15]$ is the most effective and practical method of corrosion prevention owing to its ease of use. Several authors have reported the uses of organic [16-19] and inorganic compounds [20-22] as corrosion inhibitors (CIs) and classified them depending on their mode of actions. Even though organic and inorganic inhibitors are efficient CIs at times, they pose a dangerous threat to health and ecology. Moreover, the contamination of the hydrocarbon stream might occur due to the fragmentation of the small molecule inhibitors at higher temperatures [23]. This has driven researchers towards the invention of nontoxic inhibitors that impart efficiency to the maximum intent and least impact on nature and humankind [24]. Different eco-friendly green CIs have been reported by several authors [25-27]. Nevertheless, novel approaches and current trends in CIs are in favor of use of polymers. Polymers, owing to the presence of a large number of binding sites, adsorb very well on the metal surface, hence impart superior inhibition efficiency (IE). Furthermore, multifunctionality, solubility, flexible viscosity, and the increased number of attachment points render polymers superior to their organic and inorganic counterparts. In this present investigation, we aim to review the uses of several classes of commonly used polymeric CIs in various corrosive environments.

\section{Polymers as Corrosion Inhibitors}

Synthesis of polymers as CIs is the current trend and considered a novel approach. Polymers can have various architectures such as branched, linear chains, hyperbranched, rotaxanes, cross-links, comb-like, and dendrimeric composed of long chains of repeating units. Polymers possess the advantages of multifunctionality, solubility, flexible viscosity, increased attachment points to metal surfaces, and better film-forming capabilities in comparison to the more widely used small molecule (organic or inorganic) inhibitors [28]. Smart designing of repeating functional groups in the polymer backbone having a large surface area and large number of binding moieties makes polymers capable of forming complexes with metals, which lead to an efficient CI $[3,24]$. The anchoring groups may be anionic, cationic, nonionic, or ampholytic in nature [24]. The reputation of having high thermal stability combined with the presence of heteroatoms such as $\mathrm{O}, \mathrm{N}$, and $\mathrm{S}$ that predominantly dictate the process of adsorption usually contributes superb corrosion IEs of polymers as well as plant extracts owing to the increased basicity and electron density [29]. In the following sections, we discuss different classes of polymers and their merits and demerits as CIs in various corrosive environments.

2.1. Naturally Occurring Polymers. Naturally occurring substances, also popularly known as "green inhibitors," have continued to receive more attention over the years owing to the facts that they are cheap, are ecologically friendly, and possess no real threat to the environment. Furthermore, they are renewable sources of materials and readily available. We aim to discuss some common and readily available naturally occurring polymers and their role as CIs in this section of the review.

Polyamino acids, including polymers of amino acids like glutamic acid (Glu) and aspartic acid (Asp), have been explored for their applications as antiscalants and CIs. Corresponding salts of polyamino acids such as alkali metal salts, alkyl ammonium salts, ammonium salts, and aryl ammonium salts also possess these properties [3]. Polyaspartic acid (PASP), a water-soluble, biodegradable copolymer of acetoacetamide and 3-carboxypropionamide, $\alpha$ - and $\beta$-forms of L-Asp, and occasionally containing cyclic imide (succinimide) moieties and Glu, is a polymer of this type that has been explored as a CI [30]. This biodegradable polymer has been found inhibiting sweet corrosion of mild steel (MSteel) in a simulated brine solution without dissolved oxygen. This polymer has reduced the corrosion of MSteel by $40 \%$ at room temperature, whereas the corrosion protection efficiency was found to be $70 \%$ at $50^{\circ} \mathrm{C}$ [3]. The corrosion IE of PASP for carbon steel (CSteel), at a concentration of $6 \mathrm{~g} / \mathrm{L}$, was found to be $80.3 \%$ after $72 \mathrm{~h}$ immersion in $0.5 \mathrm{M} \mathrm{H}_{2} \mathrm{SO}_{4}$ at $10^{\circ} \mathrm{C}$. The inhibitor was found to follow the Freundlich isotherm [31].

Abd-El-Nabey and his research team studied cysteine (Cys) and methionine (Met) for their corrosion inhibition of MSteel in $1 \mathrm{~N} \mathrm{H}_{2} \mathrm{SO}_{4}$ [32]. The IE increased with an increasing concentration of the inhibitor, and more than $60 \%$ inhibition was achieved with an amino acid concentration as low as $10^{-3} \mathrm{M}$. All of the amino acid inhibitors acted as a mixed-type inhibitor. The IE of alanine (Ala), Cys, and $S$-methylcysteine ( $S$-MCys) was tested for iron in aerated stagnant $1 \mathrm{M} \mathrm{HCl}$ solutions by Tafel and impedance measurements [33]. Corresponding shifts in the corrosion potential $\left(E_{\text {corr }}\right)$ values indicated that Ala acts mainly as a cathodic inhibitor, while $S$-MCys and Cys act as mixed-type inhibitors. Cys, containing a mercapto group in its molecular structure, was the most effective compared to the other inhibitors. The inhibitive effect of valine (Val), glycine (Gly), arginine 
(Arg), lysine (Lys), and Cys was also studied using weight loss (WL) and electrochemical polarization measurements [34]. Cys was found to be the best inhibitor with an efficiency of $61 \%$ obtained at a meager concentration of $10^{-3} \mathrm{M}$. The influence of sulfur-containing amino acids, namely, Met, Cys, and $\mathrm{N}$-acetylcysteine ( $\mathrm{N}$-ACys), on the corrosion behavior of MSteel in a highly concentrated solution of $\mathrm{H}_{3} \mathrm{PO}_{4}$ in the absence and presence of $\mathrm{Cl}^{-}, \mathrm{F}^{-}$, and $\mathrm{Fe}^{3+}$ ions has been investigated [35]. Ismail used electrochemical studies [36] to investigate the inhibitive effect of Cys on $\mathrm{Cu}$ metal in $0.6 \mathrm{M}$ $\mathrm{NaCl}$ and $1.0 \mathrm{M} \mathrm{HCl}$. The potentiodynamic polarization (PDP) study revealed that the presence of Cys affects mainly the cathodic process in both types of solutions, decreases the corrosion current to a great extent, and shifts the $E_{\text {corr }}$ towards more negative values. The thermodynamic study revealed that the inhibitor follows the Langmuir adsorption isotherm and demonstrates a strong physical adsorption on the metal surface. Synergistic inhibitive effect of Cys and $\mathrm{Cu}$ (II) ions on $\mathrm{Fe}$ in $0.5 \mathrm{M} \mathrm{H}_{2} \mathrm{SO}_{4}$ has been investigated [37]. Electrochemical Impedance Spectroscopy (EIS) revealed a significant increase in the polarization resistance $\left(R_{\mathrm{p}}\right)$ of the iron/solution interface in the presence of $\mathrm{Cys}$ and $\mathrm{Cu}(\mathrm{II})$ ions instead of Cys alone.

The corrosion IE of Cys, $\mathrm{N}$-ACys, and Met as environmentally safe inhibitors for the corrosion of $\mathrm{Cu}-10 \mathrm{Al}-5 \mathrm{Ni}$ alloy in $3.5 \mathrm{wt} . \% \mathrm{NaCl}$ solution was studied [38]. Cys, at a meager concentration of $6.0 \mathrm{mM}$ showed $96 \%$ IE of corrosion. Amino acids, namely, Gly, Ala, Val, Cys, Glu acid, and histidine (His), have been investigated for their corrosion inhibition of $\mathrm{Pb}$ in aqueous solutions with different $\mathrm{pH}$. The corrosion IE of $87 \%$ was recorded with Glu at a concentration of $0.025 \mathrm{M}$ [39]. The inhibitive action of $\mathrm{Cys}$ on $\mathrm{Cu}-30 \mathrm{Ni}$ alloy in aerated $0.5 \mathrm{M} \mathrm{H}_{2} \mathrm{SO}_{4}$ was explored [40]. An IE of $91 \%$ was obtained at an inhibitor concentration of $10^{-3} \mathrm{M}$. Badawy and coworkers demonstrated that Gly at a concentration as low as $0.1 \mathrm{mM}$ can impart an IE of about $85 \%$ on $\mathrm{Cu}-\mathrm{Ni}$ alloy in neutral chloride solution [41]. For low Ni content alloy $(\mathrm{Cu}-5 \mathrm{Ni})$, a remarkably high efficiency of $96 \%$ was achieved at a low concentration of $2.0 \mathrm{mM}$ Cys. Helal and Badawy studied the inhibitive action of some amino acids including phenylalanine (Phe) and Cys on $\mathrm{Mg}-\mathrm{Zn}-\mathrm{Al}$ alloy in stagnant naturally aerated chloride-free neutral solutions. Phe showed a very high efficiency of $93 \%$ at a concentration of $2 \times 10^{-3} \mathrm{~mol} \mathrm{dm}^{-3}$. The corrosion inhibition process was found to depend on the concentration of amino acid molecules on the metal surface [42].

Carbohydrate polymers are commonly used as protective coatings and metal linings. These biopolymers represent a biodegradable, ecofriendly, and chemically stable set of inhibitors that have unique inhibiting strengths and mechanistic approaches to metal surface and bulk protection [43]. Umoren et al. investigated the inhibition effect of polyethylene glycol (PEG; a synthetic polymer) and gum arabic (GA; a naturally occurring polymer) in the absence and presence of halide ions on MSteel in $0.1 \mathrm{M} \mathrm{H}_{2} \mathrm{SO}_{4}$ [44]. In the absence and presence of $0.05 \mathrm{M} \mathrm{KCl}, \mathrm{KBr}$, and $\mathrm{KI}$ at $60^{\circ} \mathrm{C}$, the IEs of GA were determined by WL measurements and were found to be $37.9,38.7,47.1$, and $59.1 \%$, respectively, while the IEs of PEG $\left(1 \times 10^{-3} \mathrm{M}\right)$ were determined to be $40.2,46.4,52.5$, and $64.3 \%$, respectively. This synergistic IE resulted from the increased surface coverage that appears from the ion pair interactions between the organic cations and the anions. The same research group also investigated the inhibitory effect of GA on AA1060 type aluminum sheets $\left(98.5 \%\right.$ purity) at $40^{\circ} \mathrm{C}$. The IEs of GA $(0.5 \mathrm{~g} / \mathrm{L})$ obtained from hydrogen evolution and thermometric methods were 74.2 and $75.9 \%$, respectively [45]. A research group from Tanzania studied the IE of gum exudates from Acacia seyal var. seyal using EIS technique and PDP measurements on MSteel in chlorinated drinking water. The IE of gum exudates at $1000 \mathrm{ppm}$ was determined to be $98.5 \%$ at $30^{\circ} \mathrm{C}$. The acacia gum from seyal var. seyal showed an IE of $96.8 \%$ at an elevated temperature of $80^{\circ} \mathrm{C}$ at $600 \mathrm{ppm}$ [46]. The inhibitory effect of guar gum (GG) on CSteel in $1 \mathrm{M} \mathrm{H}_{2} \mathrm{SO}_{4}$ was thoroughly studied, and the IE at $1500 \mathrm{ppm}$ was found to be 93.8 and $93.6 \%$ from WL and PDP measurements, respectively [47]. It was proposed that GG acted as a mixed-type inhibitor in which adsorption takes place at the electrode/solution interface. GG is a polysaccharide composed of $\beta$ 1,4-linked mannose residues to which galactose residues are 1,6-linked at every second mannose having repeated heterocyclic pyran moiety. The presence of heteroatom oxygen makes it possible to produce a coordinate-type linkage to the steel surface and make a stable chelate five-membered ring with ferrous ions. Mobin and Rizvi from Corrosion Research Laboratory, India, investigated the inhibitory effect of xanthan gum (XG) as an eco-friendly $\mathrm{CI}$ for MSteel in $1 \mathrm{M} \mathrm{HCl}$ at 30, 40, 50, and $60^{\circ} \mathrm{C}$, respectively. The maximum IE of $74.2 \%$ was achieved at a concentration of $1000 \mathrm{ppm}$ at $30^{\circ} \mathrm{C}$. The IE of XG enhanced upon the addition of very small amounts of surfactants sodium dodecyl sulfate, cetylpyridinium chloride, and Triton X-100. The increased efficiency of the XG in the presence of the surfactants was further corroborated by the quantum chemical calculations. The energy differences between the highest occupied molecular orbital (HOMO) and the lowest unoccupied molecular orbital (LUMO) were found to be $0.05 \mathrm{eV}$ and $0.02 \mathrm{eV}$ in $\mathrm{XG}$ alone and XG plus the sodium dodecyl sulfate surfactant, respectively. The smaller the energy gap between LUMO and HOMO, the higher is the IE of the inhibitor. Ultravioletvisible (UV-Vis) spectroscopic measurements suggested the formation of a complex between $\mathrm{XG}$ and $\mathrm{Fe}^{2+}$ ions released during corrosion reaction. An improvement in the surface morphology of inhibited MSteel compared with uninhibited MSteel was confirmed by scanning electron microscopy (SEM) studies [48].

The anticorrosive effect of a composite coating consisting of chitosan (CS; green matrix), oleic acid (OA), and graphene oxide (GO; nanofiller) was studied for corrosion protection of CSteel in $3.5 \mathrm{wt} . \% \mathrm{NaCl}$ solution [49]. The corrosion resistance of the nanocomposite coating was monitored using PDP and EIS. The corrosion resistance of OA-modified CS/GO film (CS/GO-OA) was found to increase by 100 -fold in comparison to the pure CS coating. The oxygen transmission rate measured for the CS/GO-OA was found to decrease by 35 -fold in comparison to the pure CS film. This decreased permeability for the CS/GO-OA justifies the enhancement in corrosion protection of the composite coating because of the 
development of a large barrier effect against the ingress of aggressive electrolyte species.

The corrosion inhibition and adsorption characteristics of hemicellulose- and cellulose-based elephant grass (Pennisetum purpureum) extract on MSteel in $1 \mathrm{M} \mathrm{HCl} \mathrm{solu-}$ tion were studied in detail [50]. The IEs were averagely above $95 \%$ at room temperature and increasing with the increasing concentration of the extract but decreasing with increasing temperatures. Fourier transform infrared spectroscopy (FT-IR) analysis of the extract showed the presence of the hydroxyl $(\mathrm{O}-\mathrm{H})$ and unsaturated $(\mathrm{C}=\mathrm{C})$ functional groups which are known to have inhibitory properties. However, FT-IR analysis of the corrosion product revealed a shift of the hydroxyl (O-H) group from 3379 to $3440 \mathrm{~cm}^{-1}$ and the unsaturated band from 1635 to $1640 \mathrm{~cm}^{-1}$. These shifts in the bands indicated an interaction between the extract and the MSteel surface resulting in inhibition. The scanning electron micrograph of the substrate immersed in the $\mathrm{HCl}$ solution without the extract revealed pitting in the metal surface, whereas pitting was rarely present in the metal substrate immersed in a solution containing $0.5 \mathrm{~g} / \mathrm{L}$ elephant grass extract. This proves the effectiveness of the extract in reducing the localized dissolution of the steel in $\mathrm{HCl}$ solution. The energy-dispersive spectroscopy (EDS) spectrum of the MSteel after immersion in $\mathrm{HCl}$ with the inhibitor showed a higher Fe peak than that of the MSteel in $\mathrm{HCl}$ without the inhibitor. This observation attests to the lower rate of iron dissolution in the acidic solution containing the extract.

El-Haddad studied the inhibition effect of hydroxyethylcellulose (HEC) for 1018 CSteel corrosion in 3.5 wt.\% $\mathrm{NaCl}$ solution using PDP, electrochemical frequency modulation (EFM), and EIS techniques. The PDP study revealed that HEC acts as a mixed-type inhibitor. The adsorption behavior of HEC on the steel surface was found to follow the Langmuir adsorption isotherm. The optimized geometry of HEC obtained by $\mathrm{DMol}^{3}$ quantum chemical calculations suggested that oxygen atoms of HEC have Mulliken atomic charges with higher electron densities. This implied that the oxygen atoms donate the unshared pair of electrons to the vacant $d$-orbitals of iron. Maximum IEs of 96.7, 94.8, and 95.5\% were measured by PDP, EFM, and EIS techniques, respectively, for the inhibitor concentration of $0.5 \mathrm{mM}$ at $25^{\circ} \mathrm{C}$ [51]. Researchers have been working extensively on the carbohydrate-based biopolymers to evaluate them as green CIs, and accommodating all of them in detail in this review is difficult. We have searched for recent literatures, listed many of them that explored and evaluated as CIs to arrest corrosion of different metals and alloys, and presented them in Table 1.

Polyphenol compounds are characterized by diverse structures that lend them various biological and chemical activities such as antioxidant activity and antibiotic and antifouling actions. The coumarin derivatives of polyphenolic compounds are characterized by at least one aromatic ring. On the contrary, regarding the flavonoid family, the two aromatic cycles are linked by a heterocycle containing oxygen atoms. Its hydroxyl group, the aromatic ring, and the $\pi$-electrons make these compounds chelate with the empty $d$-orbitals of the metal atoms. Veys-Renaux et al. studied the morphological, structural, and electrochemical effects of three polyphenolic compounds esculetol, esculin, and rutin on steel in a weak acidic medium containing $10^{-3} \mathrm{M} \mathrm{NaCl}$ at $\mathrm{pH} 4$ [52]. SEM, Raman spectroscopy, and synchrotron X-ray absorption spectroscopy (XAS) proved that a surface film was formed because of the formation of iron polyphenolate conversion products, in which $\mathrm{Fe}^{3+}$ is likely coordinated with free catechol groups. Of all the three inhibitors, esculetol formed a compact layer and acted as both anodic and cathodic inhibitors. On the contrary, rutin formed a nonflat layer and esculin formed no layer that led them to function as weaker inhibitors. Nardeli et al. studied tannin, which is a complex mixture of nontoxic and biodegradable polyphenolic compounds [53]. In this study, tannin was derived from the falvon-3-ol structure that resulted from the aqueous leaching of bark from black acacia, Acacia mearnsii de Wild. This work was aimed at investigating the effect of tannin as CI of bare and coated aluminum alloys 1200. Attenuated total reflectance Fourier transform infrared spectroscopy (FT-IR-ATR) was used to characterize tannin, and its corrosion inhibition behavior was investigated using density functional theory (DFT), open circuit potential (OCP), EIS, and scanning vibrating electrode technique (SVET). The electrochemical results revealed that tannin acted as an effective inhibitor by giving both coated and uncoated aluminum alloy samples more protection than when they were in an inhibitor less $3.5 \mathrm{wt} . \% \mathrm{NaCl}$ solution. SVET measurements demonstrated that the presence of inhibitor improved the corrosion resistance of the exposed metal when both coatings were damaged.

Plant Tragia involucrata L., which is a known source for many active components like flavonoids, tannins, alkaloids, sterols, and volatile oils, has been studied recently for its corrosion mitigation properties of low CSteel against $1 \mathrm{M} \mathrm{HCl}$ [54]. Before the initiation of the corrosion study, the plant was tested for the total phenolic and flavonoid content and antioxidant activity and they were found to be significant. Scanning electron microscopy-energy-dispersive X-ray spectroscopy (SEM-EDX), atomic force microscopy (AFM), UV-Vis, and FT-IR studies were used to study the surface morphology. At a concentration of $0.25 \mathrm{~g} / \mathrm{L}$, the inhibitor showed an efficiency of 74.8 and $88.0 \%$ in Tafel and EIS measurements, respectively. Leaf and bark extracts of Acacia tortilis have been evaluated as CIs of MSteel in seawater [55]. The extracts were found to contain polyphenols, phenolic compounds, and flavonoids. Both PDP curves and EIS studies were performed to gauge the IE of the inhibitors. The PDP study revealed that both types of extracts acted as mixed-type inhibitors. The adsorption of the inhibitors on the steel surface follows the Langmuir adsorption isotherm model and involves competitive physisorption and chemisorption mechanisms. The maximum achievable IEs were 87.6 and $72.9 \%$ for leaf and bark extracts measured by EIS, respectively. Moreover, IEs revealed by Tafel and WL techniques were in accordance with the findings revealed by the EIS study.

2.2. Synthetic Polymers. Synthetic polymers are referred to as polymers that are synthesized in the laboratory to serve as a better replacement of the natural polymers. Natural 


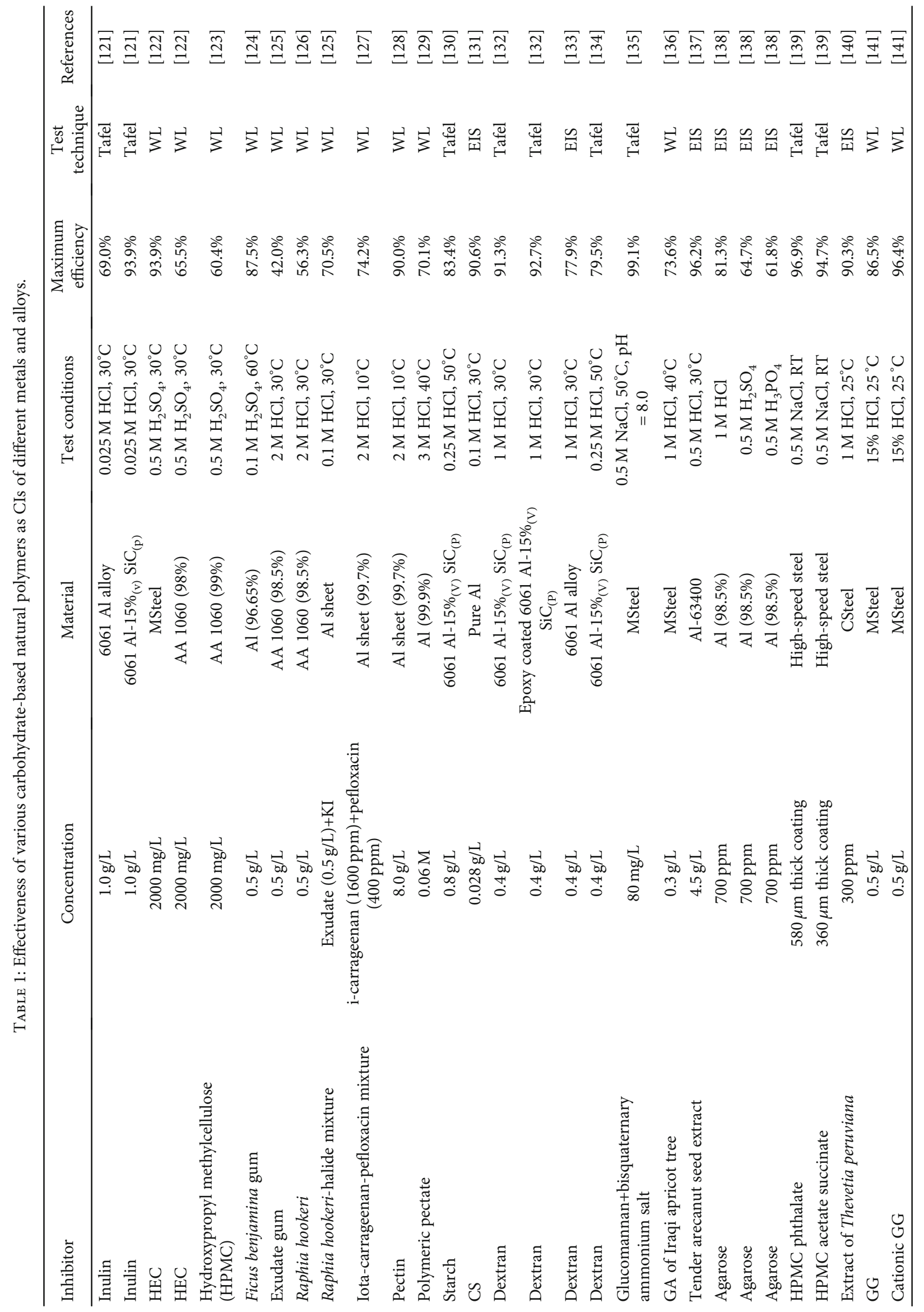


polymers, though environmetally benign, are not always soluble in the aqueous medium that renders its use disadvantageous at times. So designing new polymers to mimic the properties of existing natural polymers or synthetically modified natural polymers, if necessary, can contribute to enhanced solubility and adsorption of inhibitors hence enhanced performance. Some synthetic polymers classified by their nature are commonly used as an efficient $\mathrm{CI}$ as discussed below.

Because of the environmentally benign nature of Cys and Met, they would probably never cease to be used as CIs in their original form or as derivatives. The cyclopolymerization of $\mathrm{SO}_{2}$ and $\mathrm{N}, \mathrm{N}$-diallyl methionine ethyl ester hydrochloride in dimethyl sulfoxide via Butler's copolymerization protocol led to the formation of an environmentally benign CI, which showed an IE of impressive 99\% via WL technique at a concentration of $25 \mathrm{ppm}$ [56]. The authors further oxidized this polymer in the presence of 1 and 2 equivalents of $\mathrm{H}_{2} \mathrm{O}_{2}$ to create copolymers that contained sulfoxide and sulfone moieties, respectively [57]. The polymer that contained a sulfoxide moiety showed maximum IE of $97 \%$ at a concentration of $175 \mu \mathrm{M}$. The IEs of these polymers obtained via different corrosion measurement techniques were consistent with each other, and all inhibitors acted as mixed-type. When the monomer $N, N$-diallyl methionine ethyl ester hydrochloride was homopolymerized and oxidized subsequently in the presence of $\mathrm{H}_{2} \mathrm{O}_{2}$, it was still the polymer that contained a sulfoxide moiety to impart maximum IE of $97 \%$ at a concentration of $70.3 \mu \mathrm{M}$ [58]. An amazing IE was obtained when the ester functionality of the copolymer obtained via cyclopolymerization of $\mathrm{SO}_{2}$ and $N, N$-diallyl methionine ethyl ester hydrochloride was hydrolyzed. A simultaneous presence of sulfide, sulfoxide, and carboxylate moieties along the chain length made the polymer impart an astonishing efficiency of $99.6 \%$ via Tafel method at a low concentration of $20 \mathrm{ppm}$ [59]. Cys-based diallylamine salts were copolymerized with diallyldimethylammonium chloride [60] showed an impressive efficiency of $99.5 \%$ at a concentration of $100 \mathrm{ppm}$. The fact that all these Met- and Cys-based polymers showed these IEs in aggressive electrolyte $1 \mathrm{M} \mathrm{HCl}$ and at temperature as high as $60^{\circ} \mathrm{C}$ and that all of them are environmentally benign makes them suitable for industrial acid cleaning and descaling processes.

It is well known that sweet corrosion, caused by the presence of dissolved carbon dioxide during the enhanced oil recovery phase, can corrode J55 and N80 CSteel structures in the petrochemical industry. While nitrogen-based imidazoline inhibitors, amines and triazoles, are frequently used to tackle this issue, they are harmful and toxic, and imidazoline inhibitors can cause the anodic dissolution of CSteel to make the matter worse. Of all the classes and subclasses of naturally occurring or green CIs, CS happens to be one of the most heavily researched inhibitors because of its lowtoxic nature. However, its poor solubility and effective inhibition only at high concentration make its application restricted; therefore, chemical functionalization is a practical way to overcome these drawbacks. Ansari et al. [61] synthesized salicylaldehyde-chitosan Schiff base (SCSB) by the reaction of CS and salicyaldehyde to find its corrosion inhibition effect in 3.5 wt. $\% ~ \mathrm{NaCl}$ solution saturated with $\mathrm{CO}_{2}$ at $65^{\circ} \mathrm{C}$. WL, EIS, and PDP techniques were explored to find out the IE. A maximum IE of $95.4 \%$ was achieved through WL technique at a concentration of $150 \mathrm{mg} / \mathrm{L}$. The PDP study revealed that the inihibitor acted as mixed-type, and EIS measurement suggested that the corrosion inhibition process was kinetically controlled. Computational studies corroborated the understanding that the introduction of a salicylaldehyde moiety increased the size of the resulting SCSB molecule and also resulted in a planar strcuture. This increased size and structural planarity aided SCSB imparting better corrosion IE. There are numerous examples of chemically functionalized CS being tested for corrosion inhibition efficacy (Figure 1). Some very recent examples with their performances are mentioned in Table 2.

The application of paint or organic coating is the most common corrosion prevention technique and, ideally, would protect the metal substrate for a long time. However, sometimes a coating may not be able to provide long-lasting protection when defects appear during a metal's service lifetime. Recently, conducting polymers (CPs) have grabbed huge attention as smart coatings owing to their ability to safeguard the bare metallic surface even in defect areas when it is exposed to the corrosive environment. CPs can exist in both conducting and nonconducting states and are capable of interchanging between them in response to appropriate conditions [62]. It was shown back in 1985 that CP polyaniline (PANI) could induce a passive state in 400 series SSteel in $\mathrm{H}_{2} \mathrm{SO}_{4}$ solutions. CPs are capable of maintaining the surface potential of the substrate into the passive state where a protective oxide film is formed on the metal substrates. The CP charge that is consumed by metal oxidation is replenished by oxygen reduction within the $\mathrm{CP}$ layer. Thus, the corrosion process is prevented when the potential turns into the passive state after CP switches into the oxidation state [63]. Various $\mathrm{CPs}$, such as PANI, polythiophene (PTh), polypyrrole (PPy), and polycarbazole (PCz), are chemically and electrochemically synthesizable and commercially available. CPs' ease of synthesis coupled with their electrical conductivity makes them very attractive anticorrosive materials, and they have been in use since the 1980s [64-66].

PANI is usually considered an ideal CI because of the copiousness of nitrogen atoms in the chemical structure and the $\pi$-electrons in the benzene rings [3]. PANIs are $\mathrm{CPs}$, and their electronic properties can be varied by changing the number of electrons, protons, or both in their chemical structure (Figure 2(a)). Their conductivity increases when PANI and its derivatives are protonated at $-\mathrm{N}$ - sites below $\mathrm{pH}$ 4. The protonated species easily adsorb on the metal surface and produce an effective barrier that hinders the diffusion of aggressive ions to a greater extent [24]. PANIs have been regarded as very efficient anticorrosive coatings, and it has been reported that PANI-containing coatings with scratches and pinholes are capable of protecting steels in neutral and acidic environment by repassivation of exposed areas [67].

A new PANI from aniline was synthesized by persulfate oxidation (Figure 2(b)) and demonstrated its merits over the monomeric counterpart by conducting corrosion studies 


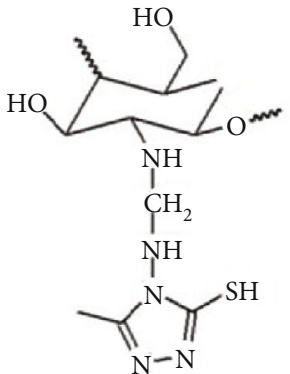

CS-AMT

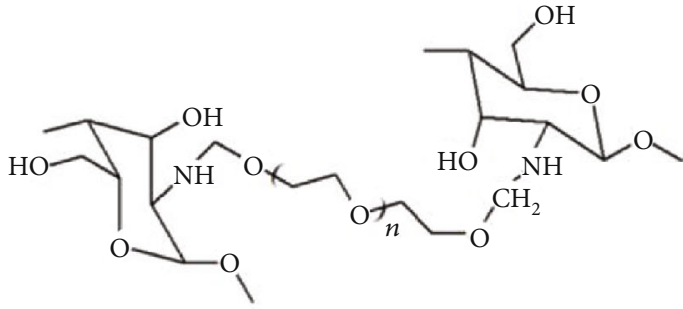

CS-PEG

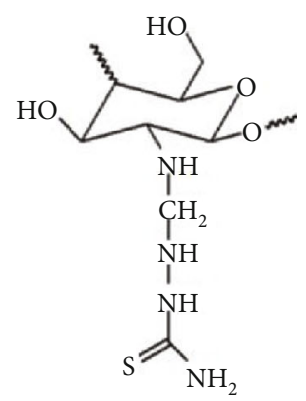

CS-TS

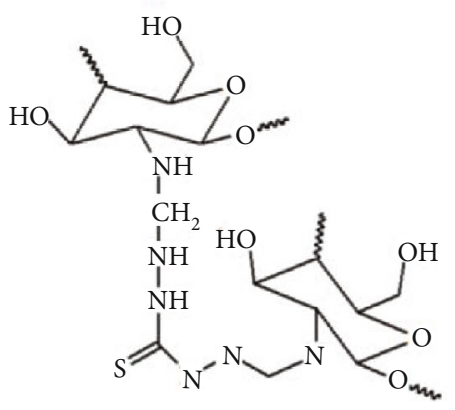

CS-TCH
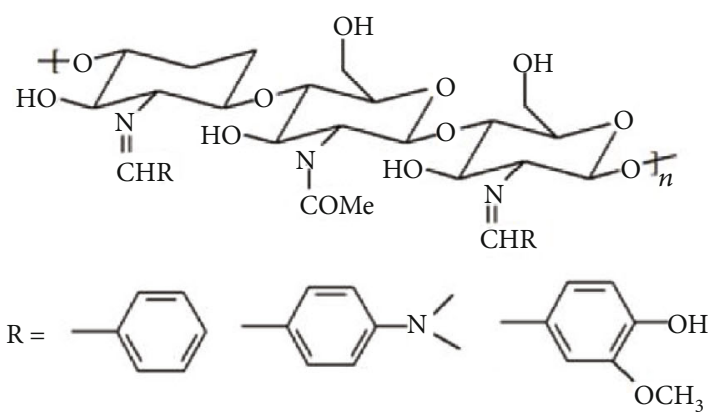

CSBs

FIGURE 1: Chemically functionalized chitosan inhibitors.

TABLE 2: Functionalized chitosan as eco-friendly CIs in different corrosive media.

\begin{tabular}{|c|c|c|c|c|c|c|}
\hline Inhibitor & Concentration & Material & Test conditions & Maximum efficiency & Test technique & References \\
\hline $\mathrm{CS}$ & $200 \mathrm{ppm}$ & MSteel & $1 \mathrm{M} \mathrm{H}_{3} \mathrm{NSO}_{3}, 35^{\circ} \mathrm{C}$ & $73.8 \%$ & WL & [142] \\
\hline $\mathrm{CS}+\mathrm{KI}$ & $200 \mathrm{ppm}(\mathrm{CS})+5 \mathrm{ppm}(\mathrm{KI})$ & MSteel & $1 \mathrm{M} \mathrm{H}_{3} \mathrm{NSO}_{3}, 35^{\circ} \mathrm{C}$ & $91.7 \%$ & Tafel & [142] \\
\hline CS-TS & $200 \mathrm{ppm}$ & MSteel & $1 \mathrm{M} \mathrm{HCl}, 35^{\circ} \mathrm{C}$ & $92.5 \%$ & EIS & [143] \\
\hline $\mathrm{CS}-\mathrm{TCH}$ & $200 \mathrm{ppm}$ & MSteel & $1 \mathrm{M} \mathrm{HCl}, 35^{\circ} \mathrm{C}$ & $93.2 \%$ & EIS & [143] \\
\hline CS-PEG & $200 \mathrm{ppm}$ & MSteel & $1 \mathrm{M} \mathrm{HCl}, 35^{\circ} \mathrm{C}$ & $93.9 \%$ & Tafel & [144] \\
\hline CS-PEG & $250 \mathrm{ppm}$ & MSteel & $1 \mathrm{M} \mathrm{H}_{3} \mathrm{NSO}_{3}, 35^{\circ} \mathrm{C}$ & $94.0 \%$ & Tafel & [145] \\
\hline $\operatorname{CSB}-1^{\mathrm{a}}$ & $150 \mathrm{ppm}$ & MSteel & $1 \mathrm{M} \mathrm{HCl}, 30^{\circ} \mathrm{C}$ & $88.5 \%$ & WL & {$[146]$} \\
\hline CSB $-2^{\mathrm{b}}$ & $150 \mathrm{ppm}$ & MSteel & $1 \mathrm{M} \mathrm{HCl}, 30^{\circ} \mathrm{C}$ & $89.9 \%$ & WL & {$[146]$} \\
\hline $\mathrm{CSB}-3^{\mathrm{c}}$ & $150 \mathrm{ppm}$ & MSteel & $1 \mathrm{M} \mathrm{HCl}, 30^{\circ} \mathrm{C}$ & $91.7 \%$ & WL & [146] \\
\hline CS-AMT & $250 \mathrm{ppm}$ & MSteel & $1 \mathrm{M} \mathrm{HCl}, 35^{\circ} \mathrm{C}$ & $96.6 \%$ & EIS & [147] \\
\hline CS-TCH & $1000 \mathrm{ppm}$ & Stainless steel (SSteel) & $3.5 \% \mathrm{NaCl}, \mathrm{RT}$ & $98.0 \%$ & Tafel & [148] \\
\hline CS-EN & $0.1 \%$ & CSteel & $5 \% \mathrm{HCl}$ & $90.0 \%$ & WL & [149] \\
\hline CS-MAA-TN & $0.1 \%$ & CSteel & $5 \% \mathrm{HCl}$ & $84.0 \%$ & EIS & [149] \\
\hline
\end{tabular}

${ }^{\mathrm{a}}$ Benzaldehyde-CSB, ${ }^{\mathrm{b}} 4$-(dimethylamino)benzaldehyde-CSB, and ${ }^{\mathrm{c}} 4$-hydroxy-3-methoxybenzaldehyde-CSB.

on pure $\mathrm{Fe}$ against $0.5 \mathrm{M} \mathrm{H}_{2} \mathrm{SO}_{4}$ in simulating industrial operations including descaling, cleaning, and pickling [28]. The study of monomeric aniline for the corrosion inhibition of pure Fe samples in $0.5 \mathrm{M} \mathrm{H}_{2} \mathrm{SO}_{4}$ for $30 \mathrm{~min}$ immersions revealed that the corrosion current decreased slightly, which started from $410 \mu \mathrm{A} \cdot \mathrm{cm}^{-2}$ for the blank to the monomeric aniline concentration of $250 \mathrm{ppm}$. Afterwards, the corrosion current showed an increasing trend and reached $569 \mu \mathrm{A} \cdot \mathrm{cm}^{-2}$ at $1000 \mathrm{ppm}$. The $R_{\mathrm{p}}$ near the vicinity of steady-state corrosion potential in the current-potential $(\eta-I)$ plots showed a decreasing trend starting from $34 \Omega \mathrm{cm}^{2}$ for the blank to $20 \Omega \mathrm{cm}^{2}$ for $1000 \mathrm{ppm}$, which was in line with the results obtained from the Tafel extrapolation method. Furthermore, EIS measurements revealed that the values of charge transfer resistance $\left(R_{\mathrm{ct}}\right)$ decreased and double-layer capacitance $\left(C_{\mathrm{dl}}\right)$ increased with increasing concentration of aniline. This opposing trend to what aniline was supposed to do has been attributed to the delocalization of the lone pair of electrons 


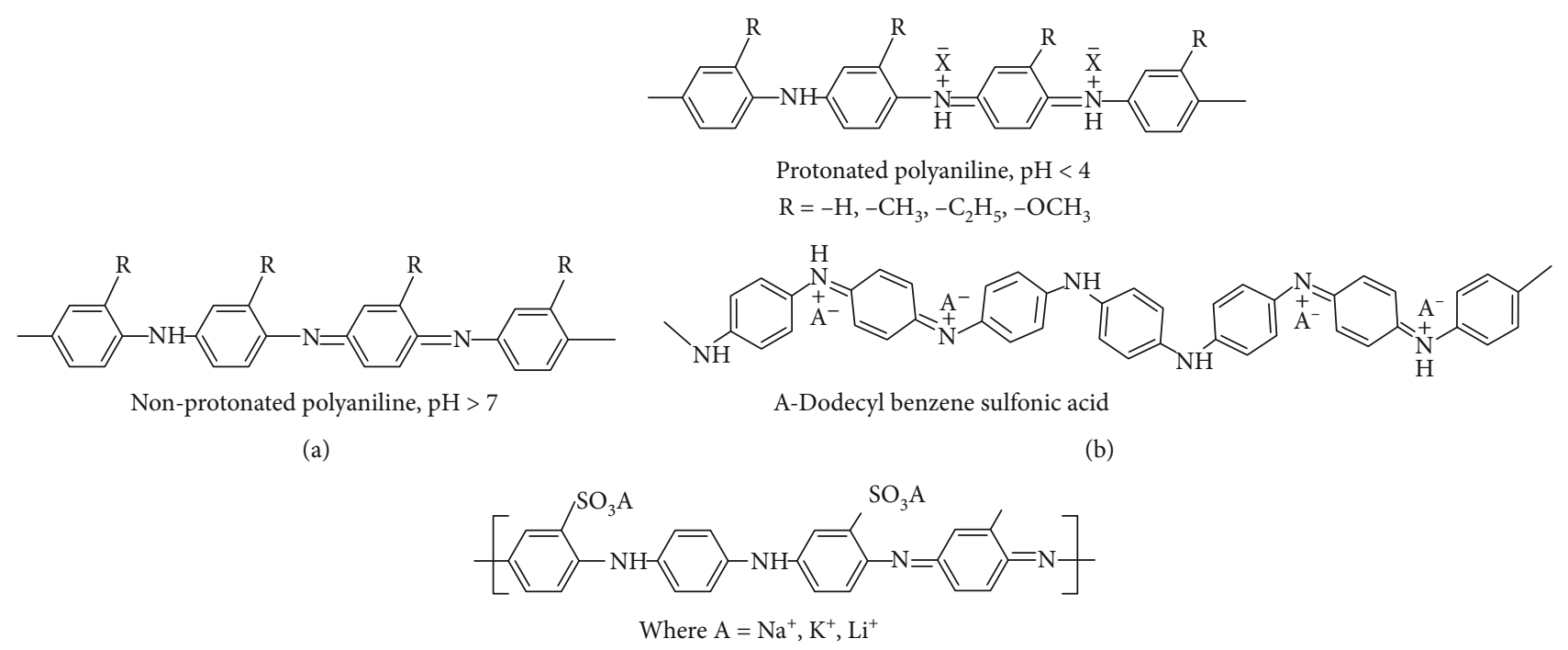

(c)

Figure 2: Structure of (a) simple, (b) modified, and (c) water-soluble PANIs.

on the nitrogen atom by the inductive effect to the phenyl group, and thus disturbing the adsorption of the aniline monomer on the metal surface. Other studies have disclosed that the $-\mathrm{CH}_{3}$-substituted or $-\mathrm{NH}_{2}$-functionalized aniline showed to be better CIs than nonfunctionalized aniline [68]. On the contrary, high-molecular weight (MW) PANI demonstrated better corrosion IEs in comparison to aniline. The Tafel extrapolation method showed that the corrosion current decreased from $410 \mu \mathrm{A} \cdot \mathrm{cm}^{-2}$ for the blank to $67 \mu \mathrm{A} \cdot \mathrm{cm}^{-2}$ for $75 \mathrm{ppm}$ of PANI. Insignificant changes in the values of $E_{\text {corr }}$, anodic beta (Tafel) coefficient $\left(\beta_{\mathrm{a}}\right.$ ), and cathodic beta (Tafel) coefficient $\left(\beta_{c}\right)$ indicated the PANIs to be a mixed-type inhibitor. The linear polarization resistance (LPR) method also showed a similar trend. The $R_{\mathrm{ct}}$ values increased from 34 to $125 \Omega \mathrm{cm}^{2}$ with a corresponding decrease in $C_{\mathrm{dl}}$ values from 2244 to $267 \mu \mathrm{F} / \mathrm{cm}^{2}$ for the increased PANI concentrations. Adsorption isotherm studies revealed that the adsorption of PANIs on the metal surface followed Temkin's adsorption behavior, and the inhibitor experienced physical adsorption due to electrostatic interactions between the charged molecules and the charged metal.

Enhancement of corrosion inhibition of various inhibitors due to the addition of halide ions [69] or metal cations particularly $\mathrm{La}^{3+}, \mathrm{Ni}^{2+}$, and $\mathrm{Cu}^{2+}[70]$ has been reported. The synergistic corrosion protection of PANI mixed with cerium ions for $\mathrm{Fe}$ in $0.5 \mathrm{M} \mathrm{H}_{2} \mathrm{SO}_{4}$ has been reported [71]. Cerium ions are known to prevent corrosion of nonferrous alloys either as inhibitors [72] or by coatings [21]. Tafel extrapolation, LPR, and EIS studies happened to reveal 83, 72 , and $70 \%$ IEs, respectively, for $100 \mathrm{ppm}$ of aniline, whereas the same studies have been conducted for $10 \times 10^{-4} \mathrm{M} \mathrm{Ce}^{4+}$ ions and were determined to be 93,90 , and $88 \%$, respectively. The synergistic study of $100 \mathrm{ppm}$ PANI and $1.0 \times 10^{-3} \mathrm{M} \mathrm{Ce}^{4+}$ ions demonstrated 92,90 , and $89 \%$ of IEs by Tafel extrapolation, LPR, and EIS studies, respectively. This enhancement in the performance of PANI upon addition of $\mathrm{Ce}^{4+}$ ions can be attributed to the formation of the metal-amine complex, which favored strong adsorption, therefore higher coverage of the complex on the iron surface.

Due to their insoluble nature in common organic solvents and water, the processability of PANIs is still unexplored. In recent years, blending, doping, compositing, or grafting of PANIs with some other materials have gained popularity to attain the desired results with high processability. A poly (o-anisidine-) (POA-) SiC composite by an in situ chemical oxidative polymerization method has been synthesized in a $p$-toluene sulfonic acid medium [73]. The morphology and the structure of the POA-SiC composite were characterized by X-ray diffraction (XRD), FT-IR, X-ray photoelectron spectroscopy (XPS), and field emission scanning electron microscopy (FESEM). The electrochemical behavior was investigated by cyclic voltammetry $(\mathrm{CV})$ measurements. A three-component POA-SiC/epoxy hybrid material was produced by introducing the POA-SiC composite to epoxy resin through solution bending method. The corrosion resistance of the three-component system was evaluated by Tafel polarization and EIS measurements in a $3.5 \mathrm{wt} . \% \mathrm{NaCl}$ solution and was compared with that of a POA/epoxy coating. The superior protection ability of the POA-SiC/epoxy coating to that of the POA/epoxy coating was ascribed to the micro-/nanostructure of the POA-SiC composite that decreased the pinhole defects of the coating by promoting a good compatibility with the epoxy resin. Zhao's research group prepared super hydrophobic PANI/polystyrene (PS) coatings by dropping PANI micro-/nanostructure on electrospinning PS nanofiber mats. The durance property and the corrosion protection ability of the resultant PANI/PS micro-/nanostructures were investigated in $0.1 \mathrm{M} \mathrm{H}_{2} \mathrm{SO}_{4}$ using EIS and PDP technique. The PANI-PFOA (PANI prepared using perfluorocaprylic acid)/PS micro-/nanostructures showed a water contact angle value as high as $153^{\circ}$, demonstrating excellent anticorrosion properties with a superb anticorrosion efficiency of 99.5\% [74]. PANIs, their derivatives and composites, PANI blends, and doped PANIs 
have been used as CIs of various metals and alloys to impart about $90 \%$ corrosion IE. Some of these PANI-based substances along with their corresponding IEs are listed and summarized in Table 3.

Most of the PANI-based substances have been used in the acid medium. Manivel et al. showed that the IEs of PANIs are highly contingent upon the concentrations of $\mathrm{H}^{+}$and $\mathrm{Cl}^{-}$ions. They demonstrated the IEs for $500 \mathrm{ppm}$ of PANI in the presence of $1.0,0.5,0.1$, and $0.05 \mathrm{M} \mathrm{H}^{+}$ions by Tafel extrapolation method were 95.6, 63.8, 60.2, and 59.9\%, respectively, while in the presence of $1.0,0.5$, and $0.1 \mathrm{M}$ $\mathrm{Cl}^{-}$ions were reported to be $62.9,57.7$, and $55.3 \%$, respectively. The lower IE in the lower concentration of $\mathrm{H}^{+}$ions has been attributed to the dominant neutral form of PANI, while the presence of higher concentrations of $\mathrm{H}^{+}$ions helps in increasing the cationic form of PANIs, i.e., anilinium cations, which undergo strong adsorption on the negatively charged metal surface. In case of $\mathrm{Cl}^{-}$ions, it is believed that $\mathrm{Cl}^{-}$ions are preferentially adsorbed on the iron electrode surface to make the surface more negative and assist the adsorption of aromatic amines. The results also showed that PANI blocked both anodic and cathodic processes of iron dissolution in $1 \mathrm{M} \mathrm{HCl}$ and it followed Langmuir's adsorption isotherm [75].

A water-soluble sulfonated PANI (Figure 2(c)) has been synthesized [76] to improve the compatibility of PANI in a wider range of brine solutions. This polymer was thermally stable up to $251^{\circ} \mathrm{C}$. The compensated sulfonated PANI made in $\mathrm{NaOH}$ at a concentration of $500 \mathrm{ppm}$ showed an IE of 98.4\% after 30 minutes of immersion in $1 \mathrm{M} \mathrm{HCl}$. KOHand $\mathrm{LiOH}$-compensated forms of the sulfonated PANI also demonstrated good IEs, although with slightly lower values. This high efficiency shown by the polymer is attributed to the presence of quaternary ammonium nitrogen and $\pi$-electrons from the aromatic nucleus that aid the polymer to be adsorbed strongly on the metal surface by minimizing the van der Waals repulsive forces between neighboring monomeric units. The sulfonated group in the polymer backbone is believed to stay facing the electrolyte to prevent it from reaching the metal surface, thus increasing the IE.

Aniline-based polymeric compounds are usually very efficient inhibitors in acidic media owing to the high degree of adsorption of the protonated form. Secondary forces, such as van der Waals forces, dispersion, or dipole interactions, dictate the interaction at the metal/solution interfaces. However, the insolubility of PANIs in aqueous and organic solvents limits their use in the alkaline/neutral medium and cooling water systems [24].

Recently, a PPy-coated CSteel surface was studied for its improved anticorrosion and antimicrobial resistance properties [77]. Galvanostatic and CV techniques in sodium salicylate solution performed the electrosynthesis of the coating on the steel surface. The electrodeposition, morphology, and stability of the coating were studied by XPS, SEM, and Raman spectroscopy. OCP, EIS, and atomic absorption spectroscopy (AAS) studies revealed the coating's anticorrosion properties. OCP studies showed that the potential of the uncoated steel reached steady state after 48 hours of immersion and a yellow precipitate was found on the surface that confirmed the oxidation of the uncoated steel in a $3 \% \mathrm{NaCl}$ medium. On the contrary, the coated steel showed an anodic shift in the $E_{\text {corr }}$ that induced an anodic protection of the surface after 140 hours of immersion. This indicates that a passive oxide layer has been formed between the polymer coating and the metal surface or in the holes of the polymer coating that provides protection against aggressive $\mathrm{Cl}^{-}$ions in the salt medium. The EIS study revealed that the diameter of the semicircle kept increasing with the prolonged presence of the coated steel in the corrosive solution. This increased $R_{\mathrm{p}}$ can be attributed to the slow redox reaction of the polymer coating that helps to maintain the electrode of the steel to be in the passive state.

PTh films were electrosynthesized on SSteel in boron trifluoride diethyl etherate solution through potentiostatic method for its anticorrosive properties study [78]. The structure, morphology, and thermal stability of the PTh films were studied by means of SEM and UV-Vis diffusing method. Tafel and EIS studies were explored to find out the anticorrosive properties of the films in $3.5 \mathrm{wt}$. $\% \mathrm{NaCl}$ solution. An efficiency of $87.4 \%$ was obtained by Tafel study after $1400 \mathrm{~s}$ of deposition time. For the EIS study, Nyquist plots were recorded for different soaking time of the PTh-modified electrodes. Collection of Nyquist plots kept going on until 1773 hours after having the first one at 40 minutes of starting the experiment. After 1773 hours, the $R_{\mathrm{ct}}$ was the lowest indicating that the protecting ability of the film is diminished now. However, this study indicates that PTh films can provide good corrosion resistance for SSteel in saltwater.

Trachli et al. electropolymerized 3-amino 1,2,4-triazole on a copper substrate in alkaline methanol solution to produce a homogenous and adherent polyamino 1,2,4-triazole (PATA) film [79]. They tested the corrosion IE of this polymer film towards copper metal in aerated $0.5 \mathrm{M} \mathrm{NaCl}$ using EIS. It is worth mentioning that the copper has a wide range of usage in microelectronic and industrial applications such as wiring technology, heat exchangers, electrostatic dissipation technology, and electromagnetic interference shielding. It is believed that the formulation of a protective layer on copper imparts good corrosion resistance. Immersion of a bulky copper electrode in aerated $0.5 \mathrm{M} \mathrm{NaCl}$ for $2 \mathrm{hrs}$ without any polymer film produced a film resistance of $150 \Omega \mathrm{cm}^{2}$. In case of uncoated copper, the cuprous oxide $\mathrm{Cu}_{2} \mathrm{O}$ film is formed on the copper electrode in the solution open to the air or the formulation of chloride salt. On the other hand, PATA-coated copper, prepared by polarizing the copper electrode at a constant potential ranged between 0.6 and $1.4 \mathrm{~V}$ and also by $\mathrm{CV}$, after one-month immersion in aerated $0.5 \mathrm{M} \mathrm{NaCl}$, showed a $R_{\mathrm{ct}}$ of more than $200 \mathrm{k} \Omega \mathrm{cm}^{2}$ provided the film-forming potential less than $1.4 \mathrm{~V}$. Thus, the protective effectiveness of this film was calculated to be greater than $99 \%$. It is important to mention that the $R_{\mathrm{ct}}$ decreased from two to seven days, then increased progressively, which attributed to the initial damage of the PATA film caused by the corrosive electrolyte followed by gradual recovery due to the formation of the protective $\mathrm{Cu}_{2} \mathrm{O}$ film.

An ideal corrosion-resistant coating is supposed to protect the metals from aqueous conditions. The coating should adhere to a wet surface, resist temperature and moisture 


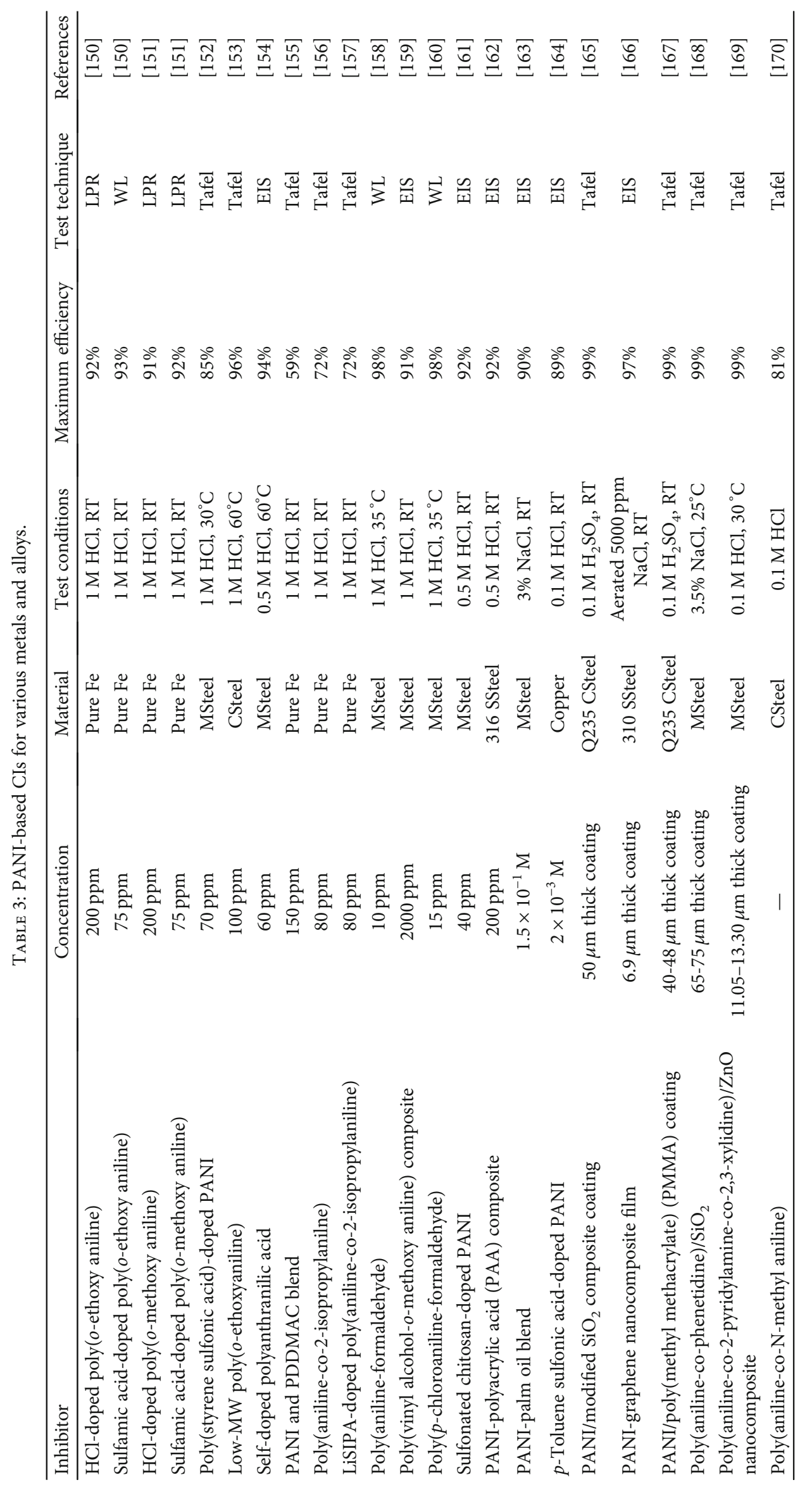


TABLE 4: Some recently reported polyamine-based corrosion inhibitors.

\begin{tabular}{lcccccc}
\hline Inhibitor & Concentration & Material & Test conditions & Maximum efficiency & Test technique & References \\
\hline Poly(benzoxacine-urethane) & - & MSteel & $3.5 \% \mathrm{NaCl}$ & $99 \%$ & Tafel & {$[171]$} \\
Poly(3-aminobenzoic acid)/PANI & - & 430 SSteel & $3.5 \% \mathrm{NaCl}$ & $88 \%$ & Tafel & {$[172]$} \\
PAPEMP & $20 \mathrm{ppm}$ & CSteel & Soft water & $88 \%$ & Tafel & {$[173]$} \\
Poly(cyanurateamine) & $2 \mathrm{ppm}$ & MSteel & $0.5-3 \mathrm{M} \mathrm{HCl}$ & $98 \%$ & Tafel & {$[174]$} \\
Poly(2-aminothiazole) & - & MSteel & $0.5 \mathrm{M} \mathrm{HCl}$ & $97 \%$ & EIS & {$[175]$} \\
\hline
\end{tabular}

changes, bind to metals as well as silicaceous materials under wet conditions, and resist autoclaving. A new series of poly(amino-quinones) (PAQ) were prepared from di-, triamines, and quinines $[80,81]$. They are very efficient in protecting metallic surfaces. They instantly bind to the metal surface with sufficient affinity to displace water. One of the major advantages of this class of polymers is its preparation from a host of readily available amines and quinones. The PAQ polymer showed IEs of 94.7 and $83.4 \%$ towards MSteel at $500 \mathrm{ppm}$ via WL technique, whereas 92.9 and $86.1 \%$ at $300 \mathrm{ppm}$ via Tafel extrapolation method and 89.2 and $84.9 \%$ at $300 \mathrm{ppm}$ by EIS measurements in $1 \mathrm{~N} \mathrm{H}_{2} \mathrm{SO}_{4}$ and $1 \mathrm{~N} \mathrm{HCl}$, respectively. The trend of shift in the $E_{\text {corr }}$ values suggested that the polymer acted as a mixed-type inhibitor. The phenomenon of more efficiency in $\mathrm{H}_{2} \mathrm{SO}_{4}$ has been attributed to the lesser adsorption of $\mathrm{SO}_{4}{ }^{2-}$ ions on the metal surface in comparison to the $\mathrm{Cl}^{-}$ions and hence more space for the inhibitors to adsorb and provide better efficiency. However, the adsorption of the PAQ polymer on the MSteel surface in both types of acids followed Temkin's adsorption isotherm.

The poly(o-toluidine) (POT) coatings were synthesized on copper substrates under cyclic voltametric conditions from an aqueous solution of sodium oxalate, and the POT coatings were examined for corrosion protection of $\mathrm{Cu}$ in an aqueous solution of $3.5 \mathrm{wt} . \% \mathrm{NaCl}$ at room temperature by PDP and CV [82]. The comparative study of bare $\mathrm{Cu}$, copper oxalate-coated $\mathrm{Cu}$, and POT-coated copper revealed the superior protection efficiency of POT-coated copper in the salt medium. The corrosion current for the bare $\mathrm{Cu}$ in the salt medium was measured to be $24.06 \mu \mathrm{A} \cdot \mathrm{cm}^{-2}$. The measured corrosion current $\left(I_{\text {corr }}\right)$ for the oxalate-coated $\mathrm{Cu}$ was $69.5 \mu \mathrm{A} \cdot \mathrm{cm}^{-2}$, which is higher than the bare $\mathrm{Cu}$. This observation revealed that the copper oxalate coating provides poor corrosion protection to $\mathrm{Cu}$. On the other hand, the $I_{\text {corr }}$ decreased from $25 \mu \mathrm{A} \cdot \mathrm{cm}^{-2}$ for bare $\mathrm{Cu}$ to $0.62 \mu \mathrm{A} \cdot \mathrm{cm}^{-2}$ for POT-coated $\mathrm{Cu}$, and the $E_{\text {corr }}$ increased from $-234 \mathrm{mV} v s$. the saturated calomel electrode (SCE) for bare $\mathrm{Cu}$ to $-163 \mathrm{mV}$ for POT-coated $\mathrm{Cu}$. This positive shift of $E_{\text {corr }}$ indicates the protection of $\mathrm{Cu}$ by POT coating. Actually, the corrosion rate of POT-coated $\mathrm{Cu}$ was found to be $\sim 0.007 \mathrm{~mm} \cdot \mathrm{y}^{-1}$, which was $\sim 40$ times lower than the bare $\mathrm{Cu}$. Furthermore, the PDP study of POT-coated $\mathrm{Cu}$ after storing them in air at $25^{\circ} \mathrm{C}$ for 7 days revealed an increase in corrosion IE with a slight lower shift in $E_{\text {corr }}$. This excellent IE of this coating has been ascribed to the adherent and uniform coverage of the metal surface as confirmed by the SEM study and the strong adsorption facilitated by the delocalized $\pi$-electrons in the polymer. Some recently reported polyamine-based corrosion inhibitors and their IEs in different corrosive media are listed in Table 4.

The research group led by Sekine investigated the behavior of corrosion inhibition of MSteel by various cationic and anionic polymers, namely, polyethyleneimine (PEI) and its derivative (PEID), polydicyanodiamide derivative (PDCDA), and polyarylamine (PAAm) as cationic polymers and polymaleic acid (PAA) derivative (PMAD) and polyacrylic acid derivative (PAAD) as anionic polymers (Figure 3 ) in different concentrations of $\mathrm{CaCl}_{2}$. Cationic polymers showed to be deficient in inhibition abilities, whereas anionic polymers demonstrated better scale-forming corrosion inhibition of MSteel [83].

A research conducted by Zhang et al. reported a cationic polyelectrolyte (quaternary polyethyleneimine) as $\mathrm{CI}$ of $\mathrm{Fe}$ in $\mathrm{H}_{2} \mathrm{SO}_{4}$. The polymer behaved as a mixed-type inhibitor and proved to be an excellent $\mathrm{CI}$, and the IE showed an increasing tendency with increasing cationic degree [84]. Quaternary PEI was also reported by same group, and its corrosion IE was tested in $\mathrm{H}_{2} \mathrm{SO}_{4}$ for low CSteel [85]. The PEIs with different molar masses (1300-750000 Da) as potential CIs for the American Iron and Steel Institute (AISI) 430 SSteel have been studied in a $3.5 \mathrm{wt} \% \mathrm{NaCl}$ solution [86]. WL and LPR measurements showed that all of the selected polymers protect this type of SSteel against uniform corrosion, whereas PEI with a molar mass of $2000 \mathrm{Da}$ provides the best corrosion protection against localized corrosion, as demonstrated by cyclic polarization measurements. PEI as CI of the American Society for Testing and Materials (ASTM) 420 SSteel in 3 wt.\% aqueous $\mathrm{NaCl}$ solution was also studied. Cyclic polarization measurements showed that PEI can act as an inhibitor against pitting corrosion. The WL test revealed that PEI can show remarkable IE against uniform corrosion. Furthermore, it has also been shown that once the protective layer is formed, it becomes very stable even in a noninhibited $\mathrm{NaCl}$ solution [87].

The corrosion inhibiting action of the polyphosphate derivative of guanidine and urea copolymer (PGUC) (Figure 4) for Armco Fe in $1 \mathrm{M} \mathrm{HCl}$ at $30^{\circ} \mathrm{C}$ was studied using EIS. The experimental results revealed that the inhibitor imparted an efficiency of $91.0 \%$ at a concentration of $11.5 \mathrm{~g} / \mathrm{L}$. The adsorption of PGUC followed Temkin's isotherm, and the low negative values of the standard free energy of adsorption $\left(\Delta G_{\text {ads }}^{\circ}\right)$ indicated that the adsorption of PGUC took place through physisorption [88]. Furthermore, the authors explored the antibacterial activity of PGUC against both Gram-positive and Gram-negative bacteria to have insight into the possibility of PGUC being used 


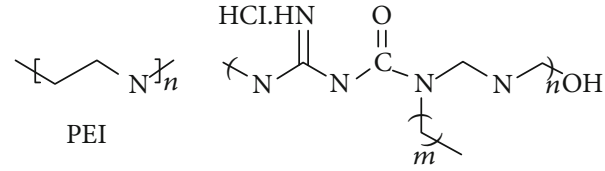

PDCDA<smiles>CCC(C)CN</smiles>

PAAm<smiles>CCCNNCNNC</smiles>

PEID

(a)

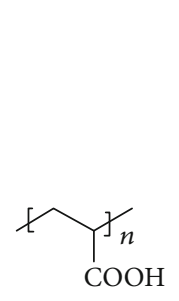

PAA<smiles>CCC(C(=O)O)C(CC)c1ccc(S(N)(=O)=O)cc1</smiles>

PAAD

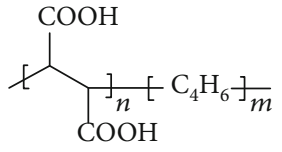

PMAD

(b)

FIgURe 3: (a) Cationic and (b) anionic polymers as corrosion inhibitors.

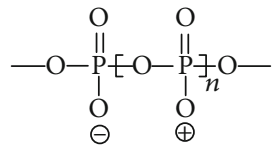

(a)

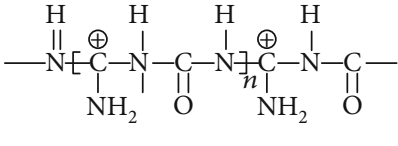

(b)
Figure 4: The molecular structure of the (a) polyphosphate derivative of guanidine and (b) urea copolymer (PGUC).

as a biocorrosion agent. The minimal inhibition concentration (MIC) measurements showed that the inhibitor is more efficient against the Gram-positive bacteria than Gramnegative bacteria. The MIC measured for the Gram-positive bacteria Staphylococcus aureus was of ca. 6-fold lower than the efficient inhibitory concentration of PGUC $(11.5 \mathrm{~g} / \mathrm{L})$. On the contrary, the MICs measured for the Gram-negative bacteria Escherichia coli and Pseudomonas aeruginosa were of $c a$. 2.7-fold and of $c a .10 .9$ higher than this concentration.

A surface-active water-soluble hyperbranched polyamideester (Hb-PAE) was synthesized through bulk polycondensation reaction between maleic anhydride and diisopropanolamine [89]. Hb-PAE was tested as a CI of plain CSteel in neutral (distilled water) and acidic $(1 \mathrm{~N} \mathrm{HCl})$ media using WL technique. The inhibitor showed an efficiency of $88.6 \%$ and $92.9 \%$ at a concentration of $0.1 \mathrm{M}$ in the acidic and neutral media, respectively. Al-Sabagh et al. synthesized a new polyamide based on thiourea and tartaric acid, as a CI of CSteel in a $1 \mathrm{M} \mathrm{HCl}$ acidic medium [90]. The IE was measured using WL, PDP, and EIS techniques. The inhibitor imparted maximum efficiency of $90.6 \%$ at a concentration of $250 \mathrm{ppm}$. The results obtained from different IE measurement techniques were in good agreement. The adsorption of the inhibitor molecule on the steel surface was found to obey the Langmuir isotherm model, and both SEM and EDX proved the existence of a protective film on the MSteel surface techniques.

A new series of thiazole-based polyamides containing a diarylidenecyclohexanone moiety was synthesized by Aly and
Hussein using low-temperature solution polycondensation technique [91]. The polymers were synthesized by the reaction of a thiazole-based monomer, namely, bis(2-aminothiazol-4ylbenzylidene)cyclohexanone, with different aliphatic and aromatic diacid chlorides using $N$-methylpyrrolidone, and in the presence of anhydrous $\mathrm{LiCl}$ as a catalyst. Polymers made with terephthaloyl chloride (Figure 5(a)) and biphenyldicarbonyl chloride (Figure 5(b)) were tested as CIs of CSteel in $0.5 \mathrm{M} \mathrm{H}_{2} \mathrm{SO}_{4}$ at $40^{\circ} \mathrm{C}$ using the Tafel extrapolation method. The polymer carrying a terephthaloyl chloride moiety imparted an efficiency of $98.2 \%$ at a concentration of $1.0 \mathrm{mg} \cdot \mathrm{L}^{-1}$, and the polymer carrying a biphenyldicarbonyl chloride moiety imparted an efficiency of $87.7 \%$ at a concentration of $0.5 \mathrm{mg} \cdot \mathrm{L}^{-1}$.

The high reactivity of vinyl monomers makes them easily polymerized by either anionic, cationic, irradiation, or free radical initiators. The water solubility of vinyl monomers facilitates the polymerization in water. Vinyl polymers containing polar substituents such as pyrrolidones and pyridines show ionic and thermal conductivity both in doped and undoped states [24]. The corrosion inhibition of poly(4vinylpyridine-poly(3-oxide-ethylene)tosyle) for $\mathrm{Fe}$ in $\mathrm{H}_{2} \mathrm{SO}_{4}$ at $80^{\circ} \mathrm{C}$ using WL, PDP, and EIS measurements was studied [92]. The efficiencies obtained from different corrosion measurement techniques were in good agreement. Surprisingly, the polymer showed very high efficiencies of 100,98 , and $100 \%$ at $2.5 \times 10^{-8} \mathrm{M}$ in WL, Tafel extrapolation, and EIS measurements, respectively. The IE of poly(4-vinylpyridine isopentyl bromide) was studied by the same research group for pure $\mathrm{Fe}$ in $1 \mathrm{M} \mathrm{H}_{2} \mathrm{SO}_{4}$. At $10^{-5} \mathrm{M}$ concentration, the polymer showed IEs of 100 and $97 \%$ in WL and Tafel extrapolation methods, respectively [93].

The corrosion protection efficiency of the poly $(N$-vinylpyrrolidone)- $b$-polyurethane- $b$-poly( $N$-vinylpyrrolidone) (PNVP-PU) triblock copolymer on MSteel in a $0.5 \mathrm{M} \mathrm{H}_{2} \mathrm{SO}_{4}$ medium was studied [94]. The copolymer showed a maximum efficiency of $98 \%$ at $1600 \mathrm{ppm}$, and the EIS 


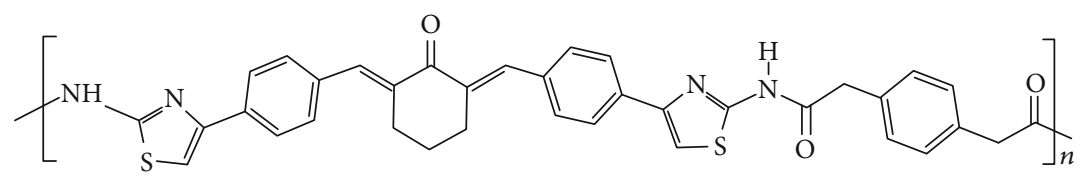

(a)

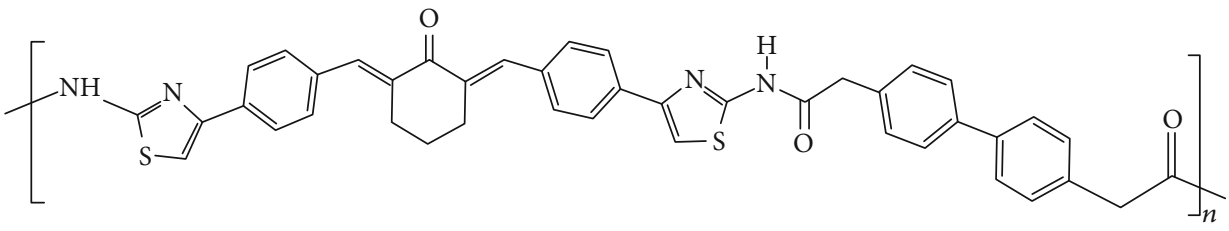

(b)

Figure 5: Copolymer of bis(2-aminothiazol-4-ylbenzylidene) cyclohexanone and (a) terephthaloyl chloride and (b) biphenyldicarbonyl chloride.

measurements revealed that the polymer inhibits MSteel corrosion by adsorbing on the MSteel surface to form the pseudocapacitive interface. The adsorption of the polymer on the MSteel surface obeyed the Langmuir adsorption isotherm and involves both the physisorption and chemisorption mechanisms. AFM and SEM analyses showed that the polymer established a protective film on the MSteel surface. Quantum chemical calculations revealed that the HOMO of PNVP-PU is distributed over the entire aromatic ring of the phenyl-diurethane and on the $\mathrm{N}$ and $\mathrm{O}$ heteroatoms of the diurethane (dicarbamate) group. This implies that PNVP-PU can interact with the metal atom by donating charges from the electron-rich phenyl-diurethane centers to the suitable vacant orbitals of the metal. The LUMO of PNVP-PU was found to be distributed over the $\pi$-electron centers of the pyrrolidinone group and also on the neighboring $\mathrm{Br}$ heteroatom and the adjacent carboxylate group. This suggests that PNVP-PU can accept charges using the electron-deficient centers around the unsaturated pyrrolidinone group and the electronegative $\mathrm{Br}$ atom. Molecular dynamic simulation studies computed the energy of interaction between PNVP-PU and Fe (110) surface to be $-365.2 \mathrm{kcal} / \mathrm{mol}$. The equilibrium configuration of PNVP$\mathrm{PU}$ revealed that the molecule adopts near-flat orientation on the Fe (110) surface. This ensures strong interaction between the inhibitor molecule and Fe. The anticorrosive property of Lumiflon (LU; fluoroethylene/vinyl ether alternating copolymer)/xylene/ $\mathrm{TiO}_{2}$ coating on electronic boards was investigated [95]. The anticorrosive properties of the coatings were studied using a PDP technique depositing the coatings on a model substrate, aluminum alloy AA 2024. The cathodic current densities of the LU/xylene coatings and the $\mathrm{LU} / x y$ lene/ $/ \mathrm{TiO}_{2}$ coatings were found to be $10^{-9}$ and $10^{-10} \mathrm{~A} / \mathrm{cm}^{2}$, respectively. This implies that the addition of $\mathrm{TiO}_{2}$ nanoparticles contributed to the protective properties of the coatings. The contact angles were also determined for $\mathrm{LU} / x y$ lene and $\mathrm{LU} / x y l e n e / \mathrm{TiO}_{2}$ coatings deposited on AA 2024 alloy. It was found that the addition of $\mathrm{TiO}_{2}$ nanoparticles increased the contact angle value for LU/xylene coatings from $80^{\circ}$ to $90^{\circ}$ for $\mathrm{LU} / x y l e n e / \mathrm{TiO}_{2}$ coatings. Moreover, optical microscopy and Raman spectroscopy were used to study the coverage of the most critical spots of the electronic boards, and it was found that the boards coated with eight layers of $\mathrm{LU} / x y l e n e / \mathrm{TiO}_{2}$ coating were entirely covered and did not show any cracks.

The IE of PEG and polyvinylpyrrolidone (PVP) and synergistic effect of polyethylene-PVP blends for MSteel corrosion in $0.5 \mathrm{M} \mathrm{H}_{2} \mathrm{SO}_{4}$ at temperature range of $30-60^{\circ} \mathrm{C}$ were explored. It was found that the IE increased with increasing concentration of the homopolymers and decreased with increasing temperature. IE was found to be increasing with an increase in the concentration of the blends and determined to be highest for the (PEG:PVP) blending ratio of $1: 3$ [96]. The inhibition effect of PVP10 (MW = 10,000 Da) and PVP45 (MW $=45,000 \mathrm{Da})$ on the corrosion of 316 SSteel was studied by Khaled. The IE was found to increase with increasing MW of PVP [97].

The inhibiting effects of 2,6-ionen and 2,10-ionen type polyvinylbenzyltrimethyl-ammonium chloride and latex on low CSteel in $0.1 \mathrm{M} \mathrm{HCl}$ by PDP and EIS techniques over the temperature range of $20-60^{\circ} \mathrm{C}$ at different inhibitor concentrations were investigated [98]. The efficiency was found to increase with increasing concentration. The degree of shift in $E_{\text {corr }}$ values revealed that the studied inhibitors behaved as anodic inhibitors. Umoren et al. explored the IE and adsorption characteristics of two water-soluble polymers, namely, PEG and polyvinyl alcohol (PVA), on MSteel in $0.1 \mathrm{M} \mathrm{H}_{2} \mathrm{SO}_{4}$ at $60^{\circ} \mathrm{C}$. The IE increased with increasing concentrations and temperatures. The inhibitors (PVA and PEG) were found to obey the Langmuir, Temkin, and Freundlich adsorption isotherms at all concentrations and temperatures studied. PEG was found to be a better inhibitor than PVA [45].

Acrylic acid is an embryo toxin, and acrylamide is a neurotoxin, while their respective polymers are found to be nonhazardous [24]. An array of acrylic-based polymers has been synthesized as hydrogels and has been exploited for different applications based on their sensitivity towards heat, light, and $\mathrm{pH}$. In this context, corrosion protection properties of some acryl-based polymers have been highlighted. The effect of static and hydrodynamic conditions (0-2000 rpm) on corrosion inhibition of a water-based acrylic terpolymer, methyl methacrylate (MMA)/butyl acrylate/acrylic acid, was investigated [99]. The study was carried out on the Society 
of Automotive Engineers (SAE) 1018 steel in simulated sour petroleum corrosive solution (NACE 1D196) by alternate current/direct current (AC/DC) electrochemical tests. Increase in rotation speed increased the corrosion rate; however, the corrosion IE also increased which was ascribed to the enhanced mass transport of inhibitor molecules to the metal surface. The thermodynamic study disclosed that the terpolymer obeys the Langmuir adsorption isotherm and adsorbs chemically onto the surface. The efficiency of the dispersed magnetite core-shell nanogel polymer poly(2-acrylamido-2-methylpropane sulfonic acid) and its copolymers with acrylic acid and acrylamide magnetic nanogels was studied as CIs. The study was conducted for carbon steel in $1 \mathrm{M}$ $\mathrm{HCl}$ employing various electrochemical techniques, such as PDP and EIS. The results revealed that the nanogels showed increasing efficiency with increasing concentrations and temperatures and acted as mixed inhibitors. The thermodynamic study revealed that the adsorption of nanogel particles was found to fit the Langmuir isotherm and followed chemisorption [100]. Umoren and his team studied the corrosion inhibition behavior of bulk nanocrystalline ingot iron (BNII) which was fabricated from coarse polycrystalline ingot iron (CPII) by PAA in $0.1 \mathrm{M} \mathrm{H}_{2} \mathrm{SO}_{4}$ using EIS and PDP techniques. The results revealed that $\mathrm{PAA}$ inhibited the acidinduced corrosion of both types of metal specimens with greater effect noted for BNII. Microstructures of the iron samples have contributed to the variation in IE shown by PAA. Synergistic inhibition effect, upon the addition of iodide ions to PAA, was observed in case of CPII, while for BNII IE was marginally increased [96].

The different feed ratios of $N$-(methacryloyloxymethyl)benzotriazole (MMBT) and MMA were used to synthesize different forms of copolymers, and their role as CIs of MSteel was studied in $0.1 \mathrm{M} \mathrm{HCl}$ using PDP and EIS methods. Variation in the composition of the copolymers showed different corrosion protection efficiencies. The copolymer obtained from the 1:1 molar ratio of MMBT and MMA exhibited better protection efficiency than other combinations [101]. Palmitic acid PAAm was synthesized by Han and Liu and used to study the corrosion inhibition of X-65 CSteel [102]. The result showed maximum IE of $78.1 \%$ at $0.1 \mathrm{~g} / \mathrm{L}$ inhibitor concentration via WL method, and the inhibition was of cathodic-type. The inhibitive effect of PAAm grafted with fenugreek mucilage (Fen), a natural grade polysaccharide, on the corrosion of MSteel in $0.5 \mathrm{M} \mathrm{H}_{2} \mathrm{SO}_{4}$ has been investigated by EIS, PDP, and WL methods [103]. The polymer, Fen- $g$-PAAm, showed an IE of $78 \%$ at a meager concentration of $1 \mathrm{ppm}$ and efficiency as high as $96 \%$ at $100 \mathrm{ppm}$. The polarization study revealed that the polymer acted as a predominantly cathodic inhibitor. The adsorption of this inhibitor on the MSteel surface obeyed the Langmuir adsorption isotherm.

Unlike the nitrogen-containing polymeric CIs, which adsorb on the metal surface, polysulfides react with $\mathrm{Fe}$ to form Fe disulfides that can abate the corrosion rate in very harsh corrosive environment. The metal disulfide coating can be continuously replenished by the continuous addition of reactants (either disulfide source or ferrous ions), which provides a more dynamic solution to corrosion. Polysulfides are one of the well-recognized polymeric CIs in the petrochemical industry. Additionally, polysulfides can also prevent a dangerous phenomenon named "hydrogen blistering" or "hydrogen attack" that results when process streams with hydrogen sulfide pass through ferrous ion pipes with liquid water. Though the mechanism was not completely understood, it is believed that the hydrogen sulfide reacts with $\mathrm{Fe}$ to form Fe sulfide and atomic hydrogen. The atomic hydrogen is not deleterious for the system in itself but can pose a significant threat when it reaches and concentrates on areas with some imperfections and exerts pressure after combining with another atomic hydrogen to create a molecular hydrogen. The pressure that builds up inside causes blistering [3].

Polysulfides not only act as CIs; their presence in the process stream can also cause synergistic advantages for the inhibition [104]. It can prevent the hydrogen embrittlement by controlling $\mathrm{CN}^{-}$concentration, which causes the formation of $\mathrm{HCN}$ amine salts. $\mathrm{HCN}$, in the upper part of regeneration towers, decomposes to form $\mathrm{H}^{+}$ions that infiltrate the metal to yield molecular hydrogen that causes hydrogen embrittlement. Moreover, polysulfides react with arsenic and mercury to produce insoluble species that can be filtered out from the stream. Organic polysulfides of the type R-(S) $)_{x}-\mathrm{R}^{\prime}$ have demonstrated corrosion protection against naphthenic acid at very high temperatures [105]. Naphthenic acids cause severe corrosion damage in the refining distillation units at temperatures ranging from 400 to $790^{\circ} \mathrm{F}$. While amine and amidebased CIs have been quite ineffective in fighting naphthenic acid corrosion, organic polysulfides, on the contrary, perform well in these conditions.

Polysulfides, in spite of having good corrosion protection efficiencies, can decompose to free sulfur and mono- or hydrosulfides when present in excessive amount at higher temperatures as shown in the reactions (1) and (2) below:

$$
\begin{aligned}
& \left(\mathrm{NH}_{4}\right)_{2}(\mathrm{~S})_{x} \longrightarrow\left(\mathrm{NH}_{4}\right)_{2}(\mathrm{~S})+(x-1) \mathrm{S} \\
& \left(\mathrm{NH}_{4}\right)_{2}(\mathrm{~S})_{x} \longrightarrow\left(\mathrm{NH}_{4}\right) \mathrm{SH}+\mathrm{NH}_{3}+(x-1) \mathrm{S}
\end{aligned}
$$

The produced sulfur can form mercaptans that are difficult to remove even by caustic washing. In addition to this, olefins can interact with these species at temperatures higher than $325^{\circ} \mathrm{F}$. Lead oxide, lead salts of the lower alkyl mercaptans, sodium polysulfide, or any other agent capable of combining with sulfur (reaction (3)) can be employed to adsorb or wash the process stream to address this dilemma.

$$
\mathrm{Pb}(\mathrm{RS})_{2}+\mathrm{S} \longrightarrow \mathrm{PbS}+\mathrm{R}-\mathrm{S}-\mathrm{S}-\mathrm{R}
$$

Moreover, the free sulfur can produce an organic disulfide, which can combine with the hydrocarbon stream and is not as precarious as the free sulfur.

Carboxylic acid derivatives and fatty acids are wellrenowned CIs for the oil and gas industries. Long-chain fatty acids of OAs are reacted with alkylene polyamines to yield polyamide CIs that are widely used in the petrochemical industries [106]. Azelaic and sebacic acids can be reacted with ammonia, di- and triethanol amines, ethanol amine, and $N, N$-diethyl-ethanol amine to produce beneficial 
carboxylate salt inhibitors in aqueous systems for drilling operations [107]. Polymaleic acids have been reacted with amines to form oil-soluble inhibitors with good anticorrosion properties and have been tested in $\mathrm{H}_{2} \mathrm{~S}$ and $\mathrm{CO}_{2}$ environments [106, 108]. Aside from the typical inhibitors produced from fatty acid polyamine reactions, polycarboxylic acids or other carboxylic acid-functionalized materials themselves are widely used CIs in various industries [3]. CIs made from polycarboxylic acids are mostly based on PAAs or polymaleic acids that have been frequently used in cooling water systems $[109,110]$. Polycarboxylic acid CIs can also be made from some unsaturated carboxylic acids such as $\alpha$-haloacrylic acid, methacyrlic acid, maleic anhydride, itaconic acid or anhydride, allyl acetic acid, vinyl acetic acid, $\beta$-carboxyethylacrylate, fumaric acid, and their salts [3].

\section{Mechanism of Corrosion Inhibition by Polymeric Inhibitors}

Corrosion is a spontaneous process, and the extent of spontaneity, i.e., the relative rate of corrosion, is contingent upon the change in standard Gibbs free energy $\left(\Delta G^{\circ}\right)$. The more negative the value of $\Delta G^{\circ}$, the higher the rate of corrosion [111]. Metals and alloys corrode to form stable corrosion products when exposed to the environment [112]. In general, CIs are used to mitigate corrosion. Interestingly, rust and scale that form because of the corrosion can also act as CIs. This is because they act as physical protective barriers after accumulating on the surface. Adsorption of an inhibitor is the first step in forming a corrosion protective film or coating in the presence of an aggressive medium that causes corrosion on the active sites. The type of interaction between the inhibitor and the metal surface is best revealed by the Langmuir adsorption isotherm [113]. If the value of $\Delta G^{\circ}$ ads is $-20 \mathrm{~kJ} \cdot \mathrm{mol}^{-1}$ or less negative, the type of interaction is known as physisorption, which arises due to the electrostatic interaction between the charged centers of inhibitor molecules and the charged metal surface. However, chemisorption occurs when the bonding strength becomes much larger where the value of $\Delta G_{\text {ads }}^{\circ}$ is around $-40 \mathrm{~kJ} \cdot \mathrm{mol}^{-1}$ or more negative [1]. In chemisorption, transfer or sharing of electron occurs from the inhibitor molecules to the metal's empty $d$-orbital through the formation of a coordinate covalent bond. Sometimes, mixed-type inhibition can occur as well, which is considered ideal for effective corrosion inhibition. Umoren and Solomon [114] pointed out that most polymers exist as polycations in widely studied acid media as proved by extensive research works. This makes it difficult for the polycations to get adsorbed onto the surfaces of positively charged metal ions. In this circumstance, anions in the aqueous medium with a smaller degree of hydration can bring more negative charges in the interface to facilitate the adsorption of polycations further via electrostatic interaction or physisorption. According to Umoren et al. [115], the inhibitor molecules exist as protonated species in equilibrium with the corresponding neutral species when chemisorption prevails. These inhibitor molecules then displace water molecules from the interface to get adsorbed onto the metal surfaces by donating the lone pair of electrons from their heteroatoms.

It is widely accepted that the presence of heteroatoms, such as $\mathrm{O}, \mathrm{N}, \mathrm{S}$, and $\mathrm{P}$, in an inhibitor increases its basicity and electron density and intensifies its IE. The lone pair of electrons on these heteroatoms and $\pi$-electrons help the inhibitors form a coordinate covalent bond with the empty $d$-orbitals of the metal atoms and facilitate adsorption of the inhibitors on the metal surface. The bond formed this way is known as chemisorption, and the electron density on the donor atom and the polarizability of the functional groups that contain the heteroatoms dictate the strength of this bond. Additionally, the presence of hydrophilic functional groups, replacement of $\mathrm{H}$ atoms attached to the $\mathrm{C}$ in a ring by the $-\mathrm{NH}_{2},-\mathrm{CHO},-\mathrm{COOH}$, or $-\mathrm{NO}_{2}$ groups, and presence of carbon numbers up to 10 in a chain are some other factors that help the inhibitors adsorb well on the metal surface [29].

In addition to the features mentioned in the preceding paragraph, some additional parameters make polymers superior to their traditional organic and inorganic counterparts. Polymers form complexes with the metal surface through their functional groups, and these complexes occupy a large surface area, thereby blanketing the surface better than other types of inhibitors and providing the metals with excellent protection in corrosive solutions [116]. Because of the presence of multiple attachment groups repeated along with the polymeric chain length, the polymeric inhibitors are better adsorbed. However, the situation becomes complex when it comes to tracing the inhibition mechanism of naturally occurring polymeric plant extracts. Because these extracts oftentimes contain multiple chemical species, it is difficult to know which one contributed more than others in corrosion prevention.

\section{Conclusions}

This review has highlighted the significance of corrosion along with different classes of CIs with a particular emphasis given to the common classes of polymers that have been widely used as CIs of various types of metals in different corrosive media. The corrosion inhibition approach has been discussed using different conducting and nonconducting polymers, copolymers, terpolymers, composites, polymer blends, doped polymers, and naturally occurring polymers. Corrosion inhibition by polymeric materials is one of the most economically viable corrosion mitigation techniques because these materials can be exploited through batch and/or continuous treatments and can lower the chance of partial or complete shutdowns even if used at a meager concentration. Even though the research on polymeric CIs bloomed a long ago, they were not successfully taken to onsite application since the performance of organic CIs thwarted the emergence of polymeric CIs. Some remarkable and innate features of these macromolecular inhibitors such as several possible attachment points, highly versatile derivatization, and better film-forming capability along with the eco-harmful nature of the inorganic inhibitors laid the foundation for the development of environmentally benign 
polymeric CIs. Mechanisms of inhibition are mainly ascribed to adsorption and contingent upon the metal, physiochemical properties of the molecule such as steric factors, functional groups, electronic structure, aromaticity at the donor atom, and $p$ orbital character of donating electrons. To put it another way, the efficiency of polymers as CIs relies not only on the corrosive environment in which it functions, the nature of the metal surface, and the electrochemical potential at the interface but also on the structure of the inhibitor itself, i.e., the number of adsorption active centers in the molecule and their charge density, the mode of adsorption, the molecular size, and the projected area of the inhibitor on the metallic surface leading to the formation of metallic complexes. It is usually desirable that a successful polymeric CI will contain heteroatoms, such as $\mathrm{O}, \mathrm{N}, \mathrm{S}$, and $\mathrm{P}$, which will increase its basicity, and the increased electron density will help increase polymers' corrosion inhibition potential. These heteroatoms are the active centers for the process of adsorption on the metal surface with the IE supposed to follow the sequence $\mathrm{O}<\mathrm{N}<\mathrm{S}<\mathrm{P}$. Most inhibitors adsorb on the surface of the metal by displacing the water molecules and forming a compact barrier. Availability of nonbonded (lone pair) and $\pi$-electrons facilitates the formation of a coordinate covalent type of bond through which the transfer of electrons from the inhibitor molecule to the metal surface could happen. The strength of this chemisorption bond relies on the polarizability of the functional group and the electron density on the donor atom. Replacement of the $\mathrm{H}$ atom attached to the $\mathrm{C}$ in the ring by a substituent group, such as the $-\mathrm{NO}_{2},-\mathrm{NH}_{2},-\mathrm{CHO}$, or $-\mathrm{COOH}$ group, culminates in a change of electron density in the metal at the point of attachment that causes retardation of anodic and cathodic reactions. The presence of multiple cationic and anionic sites within a polymer chain along with the presence of highly polarizable heteroatoms, such as $\mathrm{N}, \mathrm{P}$, and $\mathrm{S}$, causes the polymer to undergo strong adsorption on the metal surface. The presence of a hydrophobic hydrocarbon chain is highly desirable since it displaces the water molecules from the surface of the metal, makes a compact barrier, and prevents the metal from coming into contact with the corrosive water molecules any further. The advent of new technologies that will make the polymerization process more controllable to produce other architectures, such as branched, hyperbranched, and dendrimeric, will surely open up new frontiers in corrosion research.

\section{Future Outlook/Challenges}

Corrosion is a stochastic, probabilistic phenomenon, which can be tackled well by interdisciplinary approaches of electrochemistry, surface science, thermodynamics and kinetics, hydrodynamics, mechanics, metallurgy/materials science, and chemistry. The oil and gas industries lose tens of billions of dollars income and expense as treatment costs every year [2]. Corrosion inhibition is one of the most practical and cost-effective approaches in confronting corrosion. However, the chemical, refinery, and petrochemical industries need to face the challenge of dealing with corrosion issues, such as the selection and development of corrosion-resistant mate- rials, environment friendly inhibitors, and coatings. A better understanding of the corrosion mechanism in these environments is a first-order priority [117]. Importantly, chromium has been ubiquitous in our life for over a century finding applications ranging from wood treatments to corrosion prevention. However, hexavalent chromium and chromate compounds have been found to induce lung cancer and genotoxicity, respectively. Even though the health risks associated with the chromium-based inhibitors being well known and extensive research has been underway since the $1980 \mathrm{~s}$ to date, hexavalent chromium remains the benchmark corrosion preventive compound in essentially all industries [118].

In this circumstance, it is extremely important that corrosion inhibition researchers guide their focus on finding appropriate green CIs, the more the better, for appropriate conditions. Fortunately, in recent years, there has been a surge in the corrosion inhibition research community in investigating various green inhibitors. As polymers are better CIs than their organic and inorganic counterparts, corrosion researchers remain much enthusiastic in investing time on experimenting different amino acid- and carbohydratebased polymers as both scale and CIs. Even though much progress has been attained in the chemistry of inhibitors, the study of these inhibitors in different corrosive systems remains very challenging. The two main challenges associated with the inhibitors being adsorbed on the metal surface are as follows: (1) metal-inhibitor interactions and (2) transport of the CI from bulk solution to the surface of the metal. The immobilization of CIs into micro-/nanocontainers could help overcome these issues [119].

The concept of this type of coating is having nanocontainers with controlled permeability of the shell and loaded with CIs or other active agents. This technology provides an excellent opportunity of combining passive functionalities like color or barrier and active ones that are responsive to local $\mathrm{pH}$, temperature, humidity, cracks, and electrochemical potential. An autonomic response to corrosion or any other defects in the coating is a big advantage of such self-healing coatings. There are scores of publications that demonstrated this concept of nanocontainers with single functionality, i.e., the release of one CI using one triggering mechanism. Nevertheless, a lot of research works need to be done on extending this idea for developing multifunctional nanocontainers that are able to encapsulate several active materials and respond to different triggering impacts. The transformation of the current research achievements to the technology level is another big challenge that needs to be tackled in a priority basis as well [120].

\section{Abbreviations}

AAS: $\quad$ Atomic absorption spectroscopy

AC: $\quad$ Alternate current

AFM: $\quad$ Atomic force microscopy

AISI: American Iron and Steel Institute

Ala: Alanine

AMT: 4-Amino-5-methyl-1,2,4-triazole-3-thiol

Arg: $\quad$ Arginine

Asp: $\quad$ Aspartic acid 


\begin{tabular}{|c|c|}
\hline ATR: & Attenuated total reflectance \\
\hline$\beta_{\mathrm{a}}:$ & Anodic beta (Tafel) coefficient \\
\hline$\beta_{c}^{a}:$ & Cathodic beta (Tafel) coefficient \\
\hline BNII: & Bulk nanocrystalline ingot iron \\
\hline$C_{\mathrm{dl}}:$ & Double-layer capacitance \\
\hline CI: & Corrosion inhibitor \\
\hline CP: & Conducting polymer \\
\hline CPII: & Coarse polycrystalline ingot iron \\
\hline CS: & Chitosan \\
\hline CSB: & Chitosan Schiff base \\
\hline CSteel: & Carbon steel \\
\hline CV: & Cyclic voltammetry \\
\hline Cys: & Cysteine \\
\hline$\Delta G^{\circ}:$ & Gibbs free energy \\
\hline$\Delta G_{\text {ads }}^{\circ}:$ & Gibbs free energy of adsorption \\
\hline DC: & Direct current \\
\hline DFT: & Density functional theory \\
\hline$E_{\text {corr }}:$ & Corrosion potential \\
\hline EDS: & Energy-dispersive spectroscopy \\
\hline EDX: & Energy-dispersive X-ray spectroscopy \\
\hline EFM: & Electrochemical frequency modulation \\
\hline EN: & Ethylene diamine \\
\hline Fen: & Fenugreek mucilage \\
\hline FESEM: & Field emission scanning electron microscopy \\
\hline FT-IR: & Fourier transform infrared spectroscopy \\
\hline GA: & Gum arabic \\
\hline GCC: & Gulf Cooperation Council \\
\hline GDP: & Gross domestic producnt \\
\hline GG: & Guar gum \\
\hline Glu: & Glutamic acid \\
\hline Gly: & Glycine \\
\hline GNP: & Gross national product \\
\hline GO: & Graphene oxide \\
\hline Hb-PAE: & Hyperbranched polyamide-ester \\
\hline HEC: & Hydroxyethylcellulose \\
\hline His: & Histidine \\
\hline HOMO: & Highest occupied molecular orbital \\
\hline HPMC: & Hydroxypropyl methylcellulose \\
\hline$I_{\text {corr }}:$ & Corrosion current \\
\hline IE: & Inhibition efficiency \\
\hline LiSIPA: & Lithiumsulfoisopthalic acid \\
\hline LPR: & Linear polarization resistance \\
\hline LU: & Lumiflon \\
\hline LUMO: & Lowest unoccupied molecular orbital \\
\hline Lys: & Lysine \\
\hline MAA-TN: & Methyl acrylate-triethylene tetramine \\
\hline Met: & Methionine \\
\hline MIC: & Minimal inhibition concentration \\
\hline MMA: & Methyl methacrylate \\
\hline MMBT: & $N$-(methacryloyloxymethyl)benzotriazole \\
\hline MSteel: & Mild steel \\
\hline MW: & Molecular weight \\
\hline NACE: & National Association of Corrosion Engineers \\
\hline$N$-ACys: & $N$-Acetylcysteine \\
\hline OA: & Oleic acid \\
\hline OCP: & Open circuit potential \\
\hline PAA: & Polyacrylic acid \\
\hline PAAD: & Polyacrylic acid derivative \\
\hline PAAm: & Polyarylamine \\
\hline
\end{tabular}

PANI: Polyaniline

PAPEMP: Polyamino polyether methylene phosphonate

PAQ: $\quad$ Poly(amino-quinone)

PASP: $\quad$ Polyaspartic acid

PATA: $\quad$ Poly(3-amino-1,2,4-triazole)

PCz: $\quad$ Polycarbazole

PDCDA: Polydicyanoamide derivative

PDDMAC: Poly(diallyldimethylammonium chloride)

PDP: $\quad$ Potentiodynamic polarization

PEG: $\quad$ Polyethylene glycol

PEI: $\quad$ Polyethyleneimine

PEID: $\quad$ Polyethyleneimine derivative

PFOA: Perfluorocaprylic acid

PGUC: $\quad$ Polyphosphate derivative of guanidine and urea

copolymer

Phe: $\quad$ Phenylalanine

PMAD: $\quad$ Polymaleic acid derivative

PMMA: $\quad$ Poly(methyl methacrylate)

PNVP-PU: Poly( $N$-vinylpyrrolidone)-polyurethane

POA: Poly $(o$-anisidine $)$

POT: $\quad$ Poly(o-toluidine)

PPy: $\quad$ Polypyrole

PS: $\quad$ Polystyrene

PTh: Polythiophene

PVA: Polyvinyl alcohol

PVP: $\quad$ Polyvinylpyrrolidone

$R_{\mathrm{ct}}: \quad$ Chrage transfer resistance

$R_{\mathrm{p}}$ : $\quad$ Polarization resistance

SAE: $\quad$ Society of Automotive Engineers

SCE: $\quad$ Saturated calomel electrode

SCSB: $\quad$ Salicylaldehyde-chitosan Schiff base

SEM: $\quad$ Scanning electron microscopy

S-MCys: $\quad S$-Methylcysteine

SSteel: $\quad$ Stainless steel

SVET: $\quad$ Scanning vibrating electrode technique

TCH: Thiocarbohydrazide

TS: $\quad$ Thiosemicarbazide

UV-Vis: Ultraviolet-visible

Val: $\quad$ Valine

WL: $\quad$ Weight loss

XAS: $\quad$ X-ray absorption spectroscopy

XG: $\quad$ Xanthan gum

XPS: $\quad$ X-ray photoelectron spectroscopy

XRD: $\quad$ X-ray diffraction.

\section{Conflicts of Interest}

The authors declare no conflict of interest.

\section{Authors' Contributions}

N. A. Aljeaban and L. K. M. O. Goni contributed equally to this work.

\section{Acknowledgments}

The authors gratefully acknowledge the research facilities provided by King Fahd University of Petroleum \& Minerals (KFUPM), Dhahran, Saudi Arabia. 


\section{References}

[1] P. R. Roberge, Handbook of Corrosion Engineering, McGrawHill, New York, NY, USA, Second edition, 2000.

[2] L. Popoola, A. Grema, G. Latinwo, B. Gutti, and A. Balogun, "Corrosion problems during oil and gas production and its mitigation," International Journal of Industrial Chemistry, vol. 4, no. 1, pp. 35-50, 2013.

[3] B. D. B. Tiu and R. C. Advincula, "Polymeric corrosion inhibitors for the oil and gas industry: design principles and mechanism," Reactive Functional Polymers, vol. 95, pp. 25-45, 2015.

[4] P. B. Raja, M. Ismail, S. Ghoreishiamiri et al., "Reviews on corrosion inhibitors: a short view," Chemical Engineering Communications, vol. 203, no. 9, pp. 1145-1156, 2016.

[5] L. Zhao, H. K. Teng, Y. S. Yang, and X. Tan, "Corrosion inhibition approach of oil production systems in offshore oilfields," Materials and Corrosion, vol. 55, no. 9, pp. 684-688, 2004.

[6] R. Javaherdashti, "How corrosion affects industry and life," Anti-Corrosion Methods and Materials, vol. 47, no. 1, pp. 30-34, 2000.

[7] G. H. Koch, J. Varney, N. Thompson, O. Moghissi, M. Gould, and J. Payer, International measures of prevention, application, and economics of corrosion technologies study, NACE International, Houston, HO, USA, 2016.

[8] H. L. Lim, "Assessing level and effectiveness of corrosion education in the UAE," International Journal of Corrosion, vol. 2012, Article ID 785701, 10 pages, 2012.

[9] H. Baker and H. Okamoto, ASM Handbook Volume 3: Alloy Phase Diagrams, ASM International, Ohio, 1992.

[10] L. Cecchetto, D. Delabouglise, and J. P. Petit, "On the mechanism of the anodic protection of aluminium alloy AA5182 by emeraldine base coatings: evidences of a galvanic coupling," Electrochimica Acta, vol. 52, no. 11, pp. 3485-3492, 2007.

[11] D.-K. Kim, S. Muralidharan, T. H. Ha et al., "Electrochemical studies on the alternating current corrosion of mild steel under cathodic protection condition in marine environments," Electrochimica Acta, vol. 51, no. 25, pp. 5259-5267, 2006.

[12] R. Subasri, T. Shinohara, and K. Mori, "Modified TiO2coatings for cathodic protection applications," Science and Technology of Advanced Materials, vol. 6, no. 5, pp. 501-507, 2005.

[13] B. M. Praveen, T. V. Venkatesha, Y. Arthoba Naik, and K. Prashantha, "Corrosion studies of carbon nanotubes-Zn composite coating," Surface and Coatings Technology, vol. 201, no. 12, pp. 5836-5842, 2007.

[14] A. S. Fouda, M. Abdallah, and A. Attia, "Inhibition of carbon steel corrosion by some cyanoacetohydrazide derivatives in $\mathrm{HCl}$ solution," Chemical Engineering Communications, vol. 197, no. 8, pp. 1091-1108, 2010.

[15] N. Saxena and S. Kumar, "Anisalidine derivatives as corrosion inhibitors of copper in acidic media," Protection of Metals and Physical Chemistry of Surfaces, vol. 51, no. 4, pp. 701-709, 2015.

[16] M. Finšgar and J. Jackson, "Application of corrosion inhibitors for steels in acidic media for the oil and gas industry: a review," Corrosion Science, vol. 86, pp. 17-41, 2014.
[17] G. Gece, "Drugs: a review of promising novel corrosion inhibitors," Corrosion Science, vol. 53, no. 12, pp. 38733898, 2011.

[18] B. Sanyal, "Organic compounds as corrosion inhibitors in different environments - A review," Progress in Organic Coatings, vol. 9, no. 2, pp. 165-236, 1981.

[19] S. A. A. El-Maksoud, "The effect of organic compounds on the electrochemical behaviour of steel in acidic media. A review," International Journal of Electrochemical Science, vol. 3, pp. 528-555, 2008.

[20] M. Bethencourt, F. J. Botana, J. J. Calvino, M. Marcos, and M. A. Rodriguez-Chacon, "Lanthanide compounds as environmentally-friendly corrosion inhibitors of aluminium alloys: a review," Corrosion Science, vol. 40, no. 11, pp. 1803-1819, 1998.

[21] B. R. W. Hinton, "Corrosion inhibition with rare earth metal salts," Journal of Alloys and Compounds, vol. 180, no. 1-2, pp. 15-25, 1992.

[22] S. N. Tiwari and S. Prakash, "Literature review magnesiumoxide as inhibitor of hot oil ash corrosion," Materials Science and Technology, vol. 14, no. 5, pp. 467-472, 1998.

[23] U. Straetmans, M. Soltau, and F. Straetmans, "Polymeric corrosion inhibiter for metal surfaces and the production thereof," 2013, US Patent US20130330564A1.

[24] A. A. F. Sabirneeza, R. Geethanjali, and S. Subhashini, "Polymeric corrosion inhibitors for iron and its alloys: a review," Chemical Engineering Communications, vol. 202, no. 2, pp. 232-244, 2015.

[25] P. B. Raja and M. G. Sethuraman, "Natural products as corrosion inhibitor for metals in corrosive media - A review," Materials Letters, vol. 62, no. 1, pp. 113-116, 2008.

[26] S. H. Zaferani, M. Sharifi, D. Zaarei, and M. R. Shishesaz, "Application of eco-friendly products as corrosion inhibitors for metals in acid pickling processes - A review," Journal of Environmental Chemical Engineering, vol. 1, no. 4, pp. 652657, 2013.

[27] R. Rajalakshmi, A. Prithiba, and S. Leelavathi, “An overview of emerging scenario in the frontiers of eco-friendly corrosion inhibitors of plant origin for mild steel," Journal of Chemica Acta, vol. 1, pp. 6-13, 2012.

[28] C. Jeyaprabha, S. Sathiyanarayanan, and G. Venkatachari, "Polyaniline as corrosion inhibitor for iron in acid solutions," Journal of Applied Polymer Science, vol. 101, no. 4, pp. 21442153, 2006.

[29] D. E. Arthur, A. Jonathan, P. O. Ameh, and C. Anya, "A review on the assessment of polymeric materials used as corrosion inhibitor of metals and alloys," International Journal of Industrial Chemistry, vol. 4, no. 1, p. 2, 2013.

[30] S. Roweton, S. J. Huang, and G. Swift, "Poly (aspartic acid): synthesis, biodegradation, and current applications," Journal of Environmental Polymer Degradation, vol. 5, no. 3, pp. 175181, 1997.

[31] R. Cui, N. Gu, and C. Li, "Polyaspartic acid as a green corrosion inhibitor for carbon steel," Materials and Corrosion, vol. 62, no. 4, pp. 362-369, 2011.

[32] B. A. Abd-El-Nabey, N. Khalil, and A. Mohamed, "Inhibition by amino acids of the corrosion of steel in acid," Surface Technology, vol. 24, no. 4, pp. 383-389, 1985.

[33] M. A. Amin, K. F. Khaled, Q. Mohsen, and H. A. Arida, “A study of the inhibition of iron corrosion in $\mathrm{HCl}$ solutions by 
some amino acids," Corrosion Science, vol. 52, no. 5, pp. 1684-1695, 2010.

[34] K. Barouni, L. Bazzi, R. Salghi et al., "Some amino acids as corrosion inhibitors for copper in nitric acid solution," Materials Letters, vol. 62, no. 19, pp. 3325-3327, 2008.

[35] M. S. S. Morad, A. E. H. A. Hermas, and M. S. A. Aal, "Effect of amino acids containing sulfur on the corrosion of mild steel in phosphoric acid solutions polluted with $\mathrm{Cl}^{-}, \mathrm{F}^{-}$and $\mathrm{Fe}^{3+}$ ions-behaviour near and at the corrosion potential," Journal of Chemical Technology and Biotechnology, vol. 77, no. 4, pp. 486-494, 2002.

[36] K. M. Ismail, "Evaluation of cysteine as environmentally friendly corrosion inhibitor for copper in neutral and acidic chloride solutions," Electrochimica Acta, vol. 52, no. 28, pp. 7811-7819, 2007.

[37] M. S. El-Deab, "Interaction of cysteine and copper ions on the surface of iron: EIS, polarization and XPS study," Materials Chemistry and Physics, vol. 129, no. 1-2, pp. 223-227, 2011.

[38] G. M. Abd El-Hafez and W. A. Badawy, "The use of cysteine, $\mathrm{N}$-acetyl cysteine and methionine as environmentally friendly corrosion inhibitors for $\mathrm{Cu}-10 \mathrm{Al}-5 \mathrm{Ni}$ alloy in neutral chloride solutions," Electrochimica Acta, vol. 108, pp. 860-866, 2013.

[39] N. H. Helal, M. M. El-Rabiee, G. M. A. El-Hafez, and W. A. Badawy, "Environmentally safe corrosion inhibition of $\mathrm{Pb}$ in aqueous solutions," Journal of Alloys and Compounds, vol. 456, no. 1-2, pp. 372-378, 2008.

[40] H. Saifi, M. C. Bernard, S. Joiret, K. Rahmouni, H. Takenouti, and B. Talhi, "Corrosion inhibitive action of cysteine on $\mathrm{Cu}-30 \mathrm{Ni}$ alloy in aerated $0.5 \mathrm{M} \mathrm{H} 2 \mathrm{SO} 4$, , Materials Chemistry and Physics, vol. 120, no. 2-3, pp. 661-669, 2010.

[41] W. A. Badawy, K. M. Ismail, and A. M. Fathi, "Corrosion control of $\mathrm{Cu}-\mathrm{Ni}$ alloys in neutral chloride solutions by amino acids," Electrochimica Acta, vol. 51, no. 20, pp. 41824189, 2006.

[42] N. H. Helal and W. A. Badawy, "Environmentally safe corrosion inhibition of $\mathrm{Mg}-\mathrm{Al}-\mathrm{Zn}$ alloy in chloride free neutral solutions by amino acids," Electrochimica Acta, vol. 56, no. 19 , pp. 6581-6587, 2011.

[43] P. B. Raja, M. Fadaeinasab, A. K. Qureshi et al., "Evaluation of green corrosion inhibition by alkaloid extracts of Ochrosia oppositifolia and isoreserpiline against mild steel in $1 \mathrm{M}$ $\mathrm{HCl}$ medium," Industrial and Engineering Chemistry Research, vol. 52, no. 31, pp. 10582-10593, 2013.

[44] S. A. Umoren, U. M. Eduok, and M. M. Solomon, "Effect of polyvinylpyrrolidone-polyethylene glycol blends on the corrosion inhibition of aluminium in $\mathrm{HCl}$ solution," Pigment Resin Technology, vol. 43, no. 5, pp. 299-313, 2014.

[45] S. A. Umoren, E. E. Ebenso, P. C. Okafor, and O. Ogbobe, "Water-soluble polymers as corrosion inhibitors," Pigment \& Resin Technology, vol. 35, no. 6, pp. 346-352, 2006.

[46] J. Buchweishaija and G. S. Mhinzi, "Natural products as a source of environmentally friendly corrosion inhibitors: the case of gum exudate from Acacia seyal var. seyal," Portugaliae Electrochimica Acta, vol. 26, no. 3, pp. 257-265, 2008.

[47] M. Abdallah, "Guar gum as corrosion inhibitor for carbon steel in sulfuric acid solutions," Portugaliae Electrochimica Acta, vol. 22, no. 2, pp. 161-175, 2004.

[48] M. Mobin and M. Rizvi, "Inhibitory effect of xanthan gum and synergistic surfactant additives for mild steel corrosion in 1M HCl," Carbohydrate Polymers, vol. 136, pp. 384-393, 2016.

[49] E. M. Fayyad, K. K. Sadasivuni, D. Ponnamma, and M. A. A. Al-Maadeed, "Oleic acid-grafted chitosan/graphene oxide composite coating for corrosion protection of carbon steel," Carbohydrate Polymers, vol. 151, pp. 871-878, 2016.

[50] K. K. Alaneme, S. J. Olusegun, and A. W. Alo, "Corrosion inhibitory properties of elephant grass (Pennisetum purpureum) extract: effect on mild steel corrosion in $1 \mathrm{M}$ $\mathrm{HCl}$ solution," Alexandria Engineering Journal, vol. 55, no. 2, pp. 1069-1076, 2016.

[51] M. N. El-Haddad, "Hydroxyethylcellulose used as an ecofriendly inhibitor for $1018 \mathrm{c}$-steel corrosion in $3.5 \% \mathrm{NaCl}$ solution," Carbohydrate Polymers, vol. 112, pp. 595-602, 2014.

[52] D. Veys-Renaux, S. Reguer, L. Bellot-Gurlet, F. Mirambet, and E. Rocca, "Conversion of steel by polyphenolic model molecules: corrosion inhibition mechanism by rutin, esculin, esculetol," Corrosion Science, vol. 136, pp. 1-8, 2018.

[53] J. V. Nardeli, C. S. Fugivara, M. Taryba, E. R. P. Pinto, M. F. Montemor, and A. V. Benedetti, "Tannin: a natural corrosion inhibitor for aluminum alloys," Progress in Organic Coatings, vol. 135, pp. 368-381, 2019.

[54] I.-M. Chung, S.-H. Kim, V. Hemapriya, K. Kalaiselvi, and M. Prabakaran, "Inhibition behavior of Tragia involucrata L. phenolic compounds against acidic medium corrosion in low carbon steel surface," Chinese Journal of Chemical Engineering, vol. 27, no. 3, pp. 717-725, 2019.

[55] I. H. Ali, A. M. Idris, and M. H. A. Suliman, "Evaluation of leaf and bark extracts of Acacia tortilis as corrosion inhibitors for mild steel in seawater: experimental and studies," International Journal of Electrochemical Science, vol. 14, pp. 64066419, 2019.

[56] H. A. Al-Muallem, M. A. J. Mazumder, M. K. Estaitie, and S. A. Ali, "A novel cyclopolymer containing residues of essential amino acid methionine: synthesis and application," Iranian Polymer Journal, vol. 24, no. 7, pp. 541-547, 2015.

[57] L. K. M. O. Goni, M. A. J. Mazumder, S. A. Ali, M. K. Nazal, and $\mathrm{H}$. A. Al-Muallem, "Biogenic amino acid methioninebased corrosion inhibitors of mild steel in acidic media," International Journal of Minerals, Metallurgy, and Materials, vol. 26, no. 4, pp. 467-482, 2019.

[58] M. A. J. Mazumder, "Synthesis of polymers containing residues of biogenic amino acid methionine, methionine sulfoxide and methionine sulfone and their application as inhibitors of mild steel corrosion," International Journal of Electrochemical Science, vol. 14, pp. 1040-1068, 2019.

[59] M. A. J. Mazumder, L. K. M. O. Goni, S. A. Ali, and M. K. Nazal, "Inhibition of mild steel corrosion in hydrochloric acid medium by polymeric inhibitors containing residues of essential amino acid methionine," Iranian Polymer Journal, vol. 27, no. 12, pp. 979-995, 2018.

[60] M. A. Jafar Mazumder, "Synthesis, characterization and electrochemical analysis of cysteine modified polymers for corrosion inhibition of mild steel in aqueous $1 \mathrm{M} \mathrm{HCl}$," RSC Advances, vol. 9, no. 8, pp. 4277-4294, 2019.

[61] K. R. Ansari, D. S. Chauhan, M. A. Quraishi, M. A. J. Mazumder, and A. Singh, "Chitosan Schiff base: an environmentally benign biological macromolecule as a new corrosion inhibitor for oil \& gas industries," International Journal of Biological Macromolecules, vol. 144, pp. 305-315, 2020. 
[62] P. P. Deshpande, N. G. Jadhav, V. J. Gelling, and D. Sazou, "Conducting polymers for corrosion protection: a review," Journal of Coatings Technology and Research, vol. 11, no. 4, pp. 473-494, 2014.

[63] D. W. DeBerry, "Modification of the electrochemical and corrosion behavior of stainless steels with an electroactive coating," Journal of the Electrochemical Society, vol. 132, no. 5, pp. 1022-1026, 1985.

[64] D. E. Tallman, G. Spinks, A. Dominis, and G. G. Wallace, "Electroactive conducting polymers for corrosion control," Journal of Solid State Electrochemistry, vol. 6, no. 2, pp. 73-84, 2002.

[65] M. Düdükcü, Y. A. Udum, Y. Ergün, and F. Köleli, "Electrodeposition of poly(4-methyl carbazole-3-carboxylic acid) on steel surfaces and corrosion protection of steel," Journal of Applied Polymer Science, vol. 111, no. 3, pp. 1496-1500, 2009.

[66] G. Ćirić-Marjanović, "Recent advances in polyaniline composites with metals, metalloids and nonmetals," Synthetic Metals, vol. 170, pp. 31-56, 2013.

[67] P. A. Sorensen, S. Kiil, K. Dam-Johansen, and C. E. Weinell, "Anticorrosive coatings: a review," Journal of Coatings Technology and Research, vol. 6, no. 2, pp. 135-176, 2009.

[68] B. R. Babu and R. Holze, "Corrosion and hydrogen permeation inhibition for mild steel in $\mathrm{HCl}$ by isomers of organic compounds," British Corrosion Journal, vol. 35, no. 3, pp. 204-209, 2000.

[69] N. Hackerman, E. S. Snavely, and J. S. Payne, "Effects of anions on corrosion inhibition by organic compounds," Journal of the Electrochemical Society, vol. 113, no. 7, pp. 677-681, 1966.

[70] G. N. Mu, T. P. Zhao, M. Liu, and T. Gu, "Effect of metallic cations on corrosion inhibition of an anionic surfactant for mild steel," Corrosion, vol. 52, no. 11, pp. 853-856, 1996.

[71] C. Jeyaprabha, S. Sathiyanarayanan, and G. Venkatachari, "Effect of cerium ions on corrosion inhibition of PANI for iron in $0.5 \mathrm{M} \mathrm{H}_{2} \mathrm{SO}_{4}$," Applied Surface Science, vol. 253, no. 2, pp. 432-438, 2006.

[72] A. J. Aldykewicz Jr., H. S. Isaacs, and A. J. Davenport, “The investigation of cerium as a cathodic inhibitor for aluminum-copper alloys," Journal of the Electrochemical Society, vol. 142, no. 10, pp. 3342-3350, 1995.

[73] C. Hu, Y. Li, N. Zhang, and Y. Ding, "Synthesis and characterization of a poly(o-anisidine)-SiC composite and its application for corrosion protection of steel," RSC Advances, vol. 7, no. 19, pp. 11732-11742, 2017.

[74] Y. Zhao, C. Xing, Z. Zhang, and L. Yu, "Superhydrophobic polyaniline/polystyrene micro/nanostructures as anticorrosion coatings," Reactive and Functional Polymers, vol. 119, pp. 95-104, 2017.

[75] P. Manivel, S. Sathiyanarayanan, and G. Venkatachari, "Influence of $\mathrm{H}^{+}$and $\mathrm{Cl}^{-}$ions on inhibitive performance of poly(aniline) for iron corrosion in acid," Journal of Applied Polymer Science, vol. 106, no. 6, pp. 3988-3993, 2007.

[76] S. Koul, S. K. Dhawan, and R. Chandra, "Compensated sulphonated polyaniline-correlation of processibility and crystalline structure," Synthetic Metals, vol. 124, no. 2-3, pp. 295-299, 2001.

[77] A. El Jaouhari, A. El Asbahani, M. Bouabdallaoui et al., "Corrosion resistance and antibacterial activity of electrosynthesized polypyrrole," Synthetic Metals, vol. 226, pp. 15-24, 2017.
[78] Y. Dai, "Electrosynthesis and characterization of polythiophene and corrosion protection for stainless steel," International Journal of Electrochemical Science, vol. 11, pp. 4084-4091, 2016.

[79] B. Trachli, M. Keddam, H. Takenouti, and A. Srhiri, "Protective effect of electropolymerized 3-amino 1,2,4-triazole towards corrosion of copper in $0.5 \mathrm{M} \mathrm{NaCl}$," Corrosion Science, vol. 44, no. 5, pp. 997-1008, 2002.

[80] S. Muralidharan, S. Ravichandran, S. Pitchumani, and K. L. N. Phani, "Poly(amino-quinone)s : a new class of polymers for anticorrosive applications," Journal of Materials Science Letters, vol. 19, no. 14, pp. 1299-1301, 2000.

[81] S. Muralidharan, K. L. N. Phani, S. Pitchumani, S. Ravichandran, and S. V. K. Iyer, "Polyamino-benzoquinone polymers: a new class of corrosion inhibitors for mild steel," Journal of the Electrochemical Society, vol. 142, no. 5, pp. 1478-1483, 1995.

[82] V. Shinde, S. R. Sainkar, and P. P. Patil, "Corrosion protection of low carbon steel by poly(o-toluidine) electrosynthesized from tartrate solution," in Eleventh National Conference for Electochemists (NCE- 11), Truchirapalli, India, 2003.

[83] I. Sekine, M. Sanbongi, H. Hagiuda et al., "Corrosion inhibition of mild steel by cationic and anionic polymers in cooling water system," Journal of the Electrochemical Society, vol. 139, no. 11, pp. 3167-3173, 1992.

[84] X. Zhang, X. D. Wu, J. Z. Li, H. Wang, D. Dai, and Z. L. Song, "Anticorrosion behaviors of quaternary polyethyleneimine in acidic environment," Materials Science Forum, vol. 610-613, pp. 136-141, 2009.

[85] X. G. Zhang, "Galvanic corrosion," in Uhlig's Corrosion Handbook, R. W. Revie, Ed., Wiley, New York, Third edition, 2011.

[86] M. Finšgar, S. Fassbender, S. Hirth, and I. Milošev, "Electrochemical and XPS study of polyethyleneimines of different molecular sizes as corrosion inhibitors for AISI 430 stainless steel in near-neutral chloride media," Materials Chemistry and Physics, vol. 116, no. 1, pp. 198-206, 2009.

[87] M. Finšgar, S. Fassbender, F. Nicolini, and I. Milošev, "Polyethyleneimine as a corrosion inhibitor for ASTM 420 stainless steel in near-neutral saline media," Corrosion Science, vol. 51, no. 3, pp. 525-533, 2009.

[88] M. Lebrini, F. Bentiss, N. E. Chihib, C. Jama, J. P. Hornez, and M. Lagrenée, "Polyphosphate derivatives of guanidine and urea copolymer: inhibiting corrosion effect of Armco iron in acid solution and antibacterial activity," Corrosion Science, vol. 50, no. 10, pp. 2914-2918, 2008.

[89] H. A. Mohamed and M. H. A. Rehim, "Surface active hyperbranched polyamide-ester as a corrosion inhibitor for carbon steel in both neutral and acidic media," Anti-Corrosion Methods and Materials, vol. 62, no. 2, pp. 95-102, 2015.

[90] A. M. Al-Sabagh, M. A. Migahed, and M. A. El-Raouf, "Corrosion inhibition of carbon steel during acid cleaning process by a new synthesized polyamide based on thiourea," Chemical Engineering Communications, vol. 199, no. 6, pp. 737750, 2012.

[91] K. I. Aly and M. A. Hussein, "Synthesis, characterization and corrosion inhibitive properties of new thiazole based polyamides containing diarylidenecyclohexanone moiety," Chinese Journal of Polymer Science, vol. 33, no. 1, pp. 1-13, 2015. 
[92] A. Chetouani, K. Medjahed, K. E. Sid-Lakhdar, B. Hammouti, M. Benkaddour, and A. Mansri, "Poly(4-vinylpyridinepoly(3-oxide-ethylene) tosyle) as an inhibitor for iron in sulphuric acid at $80{ }^{\circ} \mathrm{C}$," Corrosion Science, vol. 46, no. 10, pp. 2421-2430, 2004.

[93] A. Chetouani, K. Medjahed, K. E. Benabadji, B. Hammouti, S. Kertit, and A. Mansri, "Poly(4-vinylpyridine isopentyl bromide) as inhibitor for corrosion of pure iron in molar sulphuric acid," Progress in Organic Coatings, vol. 46, no. 4, pp. 312-316, 2003.

[94] S. Kumar, H. Vashisht, L. O. Olasunkanmi et al., "Experimental and theoretical studies on inhibition of mild steel corrosion by some synthesized polyurethane triblock co-polymers," Scientific Reports, vol. 6, no. 1, article 30937, 2016.

[95] M. Rodošek, L. S. Perše, M. Mihelčič et al., "Raman spectroscopy of fluoropolymer conformal coatings on electronic boards," Electronic Materials Letters, vol. 10, no. 5, pp. 935941, 2014.

[96] S. A. Umoren, Y. Li, and F. H. Wang, "Influence of iron microstructure on the performance of polyacrylic acid as corrosion inhibitor in sulfuric acid solution," Corrosion Science, vol. 53, no. 5, pp. 1778-1785, 2011.

[97] M. M. Khaled, "The effect of molecular weight on the corrosion protection properties of polyvinylpyrrolidone polymers on stainless steel," The Arabian Journal for Science and Engineering, vol. 35, pp. 29-39, 2010.

[98] G. Bereket, A. Yurt, and H. Türk, "Inhibition of the corrosion of low carbon steel in acidic solution by selected polyelectrolytes and polymers," Anti-Corrosion Methods and Materials, vol. 50, no. 6, pp. 422-435, 2003.

[99] M. V. Azghandi, A. Davoodi, G. A. Farzi, and A. Kosari, "Water-base acrylic terpolymer as a corrosion inhibitor for SAE1018 in simulated sour petroleum solution in stagnant and hydrodynamic conditions," Corrosion Science, vol. 64, pp. 44-54, 2012.

[100] A. M. Atta, O. E. El-Azabawy, H. S. Ismail, and M. A. Hegazy, "Novel dispersed magnetite core-shell nanogel polymers as corrosion inhibitors for carbon steel in acidic medium," Corrosion Science, vol. 53, no. 5, pp. 1680-1689, 2011.

[101] A. P. Srikanth, A. Lavanya, S. Nanjundan, and N. Rajendran, "Synthesis, characterization, and corrosion protection properties of poly(N-(methacryloyloxymethyl) benzotriazole-comethyl methacrylate) on mild steel," Applied Surface Science, vol. 253, no. 4, pp. 1810-1816, 2006.

[102] T. Han and J. Liu, "Facile synthesis of palmitic acid polyacrylamide and its application for steel protection from corrosion using electrochemical determination," Procedia Engineering, vol. 7, pp. 404-409, 2010.

[103] V. Srivastava, S. Banerjee, and M. M. Singh, "Inhibitive effect of polyacrylamide grafted with fenugreek mucilage on corrosion of mild steel in $0.5 \mathrm{M} \mathrm{H}_{2} \mathrm{SO}_{4}$ at $35^{\circ} \mathrm{C}$," Journal of Applied Polymer Science, vol. 116, no. 2, pp. 810-816, 2009.

[104] G. B. McGarvey, R. J. Falkiner, D. R. Slim, and B. M. Knickerbocker, "In situ generation of polysulfide ions using elemental sulfur for improved corrosion control, cyanide management, mercury management, arsine management and performance and reliability of acid gas removal equipment," 2014, US patent US8668887B2.

[105] F. Humblot, "Use of organic polysulfides against corrosion by acid crudes," 2005, WO patent WO2005103208A1.
[106] K. Oppenlaender, K. Stork, H. H. Vogel, E. Schwartz, and C. P. Jakob, "Ammonium salts of polymaleic acids, and their use as corrosion inhibitors in mineral oils," 1984, US4435298A.

[107] W. A. Higgins, "Corrosion inhibition in well-drilling operations using aqueous systems containing ammonium carboxylates," 1981, US patent US4250042A.

[108] K. Oppenlaender, K. Stork, and K. Barthold, "Ammonium salts of polymaleic acids and use as corrosion inhibitors in water-in-oil emulsions," 1984, US patent US4436639A.

[109] D. C. Parker and B. G. Clubley, “Corrosion inhibitor," 1990, US patent US4898687A.

[110] R. Crovetto, C. C. Pierce, and P. D. Deck, "Compositions and methods for inhibiting corrosion in aqueous media," 2011, US patent US8025840B2.

[111] S. Manimegalai and P. Manjula, "Thermodynamic and adsorption studies for corrosion inhibition of mild steel in aqueous media by Sargasam swartzii (brown algae)," Journal of Materials and Environmental Science, vol. 6, pp. 16291637, 2015.

[112] Y. Roh, S. Y. Lee, and M. P. Elless, "Characterization of corrosion products in the permeable reactive barriers," Environmental Geology, vol. 40, no. 1-2, pp. 184-194, 2000.

[113] J. P. F.-D. los Ríos, M. Sánchez-Carrillo, C. G. Nava-Dino et al., "Opuntia ficus-indica extract as green corrosion inhibitor for carbon steel in $1 \mathrm{M} \mathrm{HCl}$ solution," Journal of Spectroscoscopy, vol. 2015, pp. 14692-14701, 2015.

[114] S. A. Umoren and M. M. Solomon, "Recent developments on the use of polymers as corrosion inhibitors - a review," The Open Materials Science Journal, vol. 8, no. 1, pp. 39-54, 2014.

[115] S. A. Umoren, M. J. Banera, T. Alonso-Garcia, C. A. Gervasi, and M. V. Mirifico, "Inhibition of mild steel corrosion in $\mathrm{HCl}$ solution using chitosan," Cellulose, vol. 20, no. 5, pp. 25292545, 2013.

[116] S. Rajendran, S. P. Sridevi, N. Anthony, A. J. Amalraj, and M. Sundaravadivelu, "Corrosion behaviour of carbon steel in polyvinyl alcohol," Anti-Corrosion Methods and Materials, vol. 52, no. 2, pp. 102-107, 2005.

[117] F. Ropital, "Current and future corrosion challenges for a reliable and sustainable development of the chemical, refinery, and petrochemical industries," Materials and Corrosion, vol. 60, no. 7, pp. 495-500, 2009.

[118] O. Gharbi, S. Thomas, C. Smith, and N. Birbilis, "Chromate replacement: what does the future hold?," npj Materials Degradation, vol. 2, no. 1, p. 12, 2018.

[119] M. Taghavikish, N. Dutta, and N. Roy Choudhury, "Emerging corrosion inhibitors for interfacial coating," Coatings, vol. 7, no. 12, pp. 217-245, 2017.

[120] E. Shchukina, H. Wang, and D. G. Shchukin, "Nanocontainer-based self-healing coatings: current progress and future perspectives," Chemical Communications, vol. 55, no. 27, pp. 3859-3867, 2019.

[121] B. P. Charitha and P. Rao, "Carbohydrate biopolymer for corrosion control of $6061 \mathrm{Al}$-alloy and 6061Aluminum-15\%(v) $\mathrm{SiC}_{(\mathrm{P})}$ composite-Green approach," Carbohydrate Polymers, vol. 168, pp. 337-345, 2017.

[122] I. O. Arukalam, I. C. Madufor, O. Ogbobe, and E. Oguzie, "Experimental and theoretical studies of hydroxyethyl cellulose as inhibitor for acid corrosion inhibition of mild steel and aluminium," The Open Corrosion Journal, vol. 6, no. 1, pp. 1-10, 2014. 
[123] I. O. Arukalam, I. C. Madufor, O. Ogbobe, and E. E. Oguzie, "Hydroxypropyl methylcellulose as a polymeric corrosion inhibitor for aluminium," Pigment \& Resin Technology, vol. 43, no. 3, pp. 151-158, 2014.

[124] N. O. Eddy, P. O. Ameh, and A. O. Odiongenyi, "Physicochemical characterization and corrosion inhibition potential of Ficus Benjamina (FB) gumfor aluminum in $0.1 \mathrm{M}$ $\mathrm{H}_{2} \mathrm{SO}_{4}$," Portugaliae Electrochimica Acta, vol. 32, no. 3, pp. 183-197, 2014.

[125] S. A. Umoren and E. E. Ebenso, "Studies of the anti-corrosive effect of Raphia hookeri exudate gum-halide mixtures for aluminium corrosion in acidic medium," Pigment \& Resin Technology, vol. 37, no. 3, pp. 173-182, 2008.

[126] S. A. Umoren, I. B. Obot, E. E. Ebenso, and N. O. Obi-Egbedi, "The inhibition of aluminium corrosion in hydrochloric acid solution by exudate gum from Raphia hookeri," Desalination, vol. 247, no. 1-3, pp. 561-572, 2009.

[127] M. M. Fares, A. K. Maayta, and J. A. Al-Mustafa, "Corrosion inhibition of iota-carrageenan natural polymer on aluminum in presence of zwitterion mediator in $\mathrm{HCl}$ media," Corrosion Science, vol. 65, pp. 223-230, 2012.

[128] M. M. Fares, A. K. Maayta, and M. M. Al-Qudah, "Pectin as promising green corrosion inhibitor of aluminum in hydrochloric acid solution," Corrosion Science, vol. 60, pp. 112$117,2012$.

[129] R. Hassan and I. Zaafarany, "Kinetics of corrosion inhibition of aluminum in acidic media by water-soluble natural polymeric pectates as anionic polyelectrolyte inhibitors," Materials, vol. 6, no. 6, pp. 2436-2451, 2013.

[130] B. P. Charitha and P. Rao, "Protection of 6061 Al-15\%(v) $\mathrm{SiC}_{(\mathrm{P})}$ composite from corrosion by a biopolymer and surface morphology studies," Protection of Metals and Physical Chemistry of Surfaces, vol. 52, no. 4, pp. 704-713, 2016.

[131] B. A. Abd-El-Nabey, Y. M. Goher, H. A. Fetouh, and M. S. Karam, "Anticorrosive properties of chitosan for the acid corrosion of aluminium," Portugaliae Electrochimica Acta, vol. 33, no. 4, pp. 231-239, 2015.

[132] B. P. Charitha, A. Chenan, and P. Rao, "Enhancement of surface coating characteristics of epoxy resin by dextran: an electrochemical approach," Industrial and Engineering Chemistry Research, vol. 56, no. 5, pp. 1137-1147, 2017.

[133] B. P. Charitha and P. Rao, "An ecofriendly approach for corrosion control of $6061 \mathrm{Al}-15 \%_{(\mathrm{v})} \mathrm{SiC}_{(\mathrm{P})}$ composite and its base alloy," Chinese Journal of Chemical Engineering, vol. 25, no. 3, pp. 363-372, 2017.

[134] B. P. Charitha and P. Rao, "Inhibitory action of dextran on the corrosion of $6061 \mathrm{Al}-15 \%_{(\mathrm{v})} \mathrm{SiC}_{(\mathrm{P})}$ composite in $\mathrm{HCl}$ medium," Perspectives in Science, vol. 8, pp. 176-178, 2016.

[135] X. Luo, X. Pan, S. Yuan, S. Du, C. Zhang, and Y. Liu, "Corrosion inhibition of mild steel in simulated seawater solution by a green eco-friendly mixture of glucomannan (GL) and bisquaternary ammonium salt (BQAS)," Corrosion Science, vol. 125, pp. 139-151, 2017.

[136] I. M. Alwaan and F. K. Mahdi, "Natural Polymer of Iraqi Apricot Tree Gum as a Novel Corrosion Inhibitor for Mild Steel in $1 \mathrm{M} \mathrm{HCl}$ Solution," International Journal of Chemical Engineering, vol. 2016, Article ID 5706432, 7 pages, 2016.

[137] N. Raghavendra and J. I. Bhat, "Green approach to inhibition of corrosion of aluminum in $0.5 \mathrm{M} \mathrm{HCl}$ medium by tender arecanut seed extract: insight from gravimetric and electro- chemical studies," Research on Chemical Intermediates, vol. 42, no. 7, pp. 6351-6372, 2016.

[138] R. S. Nathiya, S. Perumal, V. Murugesan, P. M. Anbarasan, and V. Raj, "Agarose as an efficient inhibitor for aluminium corrosion in acidic medium: an experimental and theoretical study," Journalof Bio- and Tribo-Corrosion, vol. 3, no. 4, pp. 44-61, 2017.

[139] S.-C. Shi and C.-C. Su, "Corrosion inhibition of high speed steel by biopolymer HPMC derivatives," Materials, vol. 9, no. 8, pp. 612-620, 2016.

[140] A. S. Fouda, H. E. Megahed, N. Fouad, and N. M. Elbahrawi, "Corrosion inhibition of carbon steel in $1 \mathrm{M}$ hydrochloric acid solution by aqueous extract of Thevetia peruviana," Journalof Bio- and Tribo-Corrosion, vol. 2, no. 3, pp. 16-29, 2016.

[141] A. Biswas, S. Pal, and G. Udayabhanu, "Effect of chemical modification of a natural polysaccharide on its inhibitory action on mild steel in $15 \% \mathrm{HCl}$ solution," Journal of Adhesion Science and Technology, vol. 31, no. 22, pp. 2468-2489, 2017.

[142] N. K. Gupta, P. G. Joshi, V. Srivastava, and M. A. Quraishi, "Chitosan: a macromolecule as green corrosion inhibitor for mild steel in sulfamic acid useful for sugar industry," International Journal of Biological Macromolecules, vol. 106, pp. 704711, 2018.

[143] D. S. Chauhan, K. R. Ansari, A. A. Sorour, M. A. Quraishi, H. Lgaz, and R. Salghi, "Thiosemicarbazide and thiocarbohydrazide functionalized chitosan as ecofriendly corrosion inhibitors for carbon steel in hydrochloric acid solution," International Journal of Biological Macromolecules, vol. 107, Part B, pp. 1747-1757, 2018.

[144] V. Srivastava, D. S. Chauhan, P. G. Joshi, V. Maruthapandian, A. A. Sorour, and M. A. Quraishi, "PEG-functionalized chitosan: a biological macromolecule as a novel corrosion inhibitor," Chemistry Select, vol. 3, no. 7, pp. 1990-1998, 2018.

[145] D. S. Chauhan, V. Srivastava, P. G. Joshi, and M. A. Quraishi, "PEG cross-linked chitosan: a biomacromolecule as corrosion inhibitor for sugar industry," International Journal of Industrial Chemistry, vol. 9, no. 4, pp. 363-377, 2018.

[146] J. Haque, V. Srivastava, D. S. Chauhan, H. Lgaz, and M. A. Quraishi, "Microwave-induced synthesis of chitosan Schiff bases and their application as novel and green corrosion inhibitors: experimental and theoretical approach," ACS Omega, vol. 3, no. 5, pp. 5654-5668, 2018.

[147] D. S. Chauhan, M. A. Quraishi, A. A. Sorour, S. K. Saha, and P. Banerjee, "Triazole-modified chitosan: a biomacromolecule as a new environmentally benign corrosion inhibitor for carbon steel in a hydrochloric acid solution," RSC Advances, vol. 9, no. 26, pp. 14990-15003, 2019.

[148] K. E. L. Mouaden, D. S. Chauhan, M. A. Quraishi, and L. Bazzi, "Thiocarbohydrazide-crosslinked chitosan as a bioinspired corrosion inhibitor for protection of stainless steel in 3.5\% NaCl," Sustainable Chemistry and Pharmacy, vol. 15, pp. 100213-100221, 2020.

[149] H. Li, H. Li, Y. Liu, and X. Huang, "Synthesis of polyamine grafted chitosan copolymer and evaluation of its corrosion inhibition performance," Journal of the Korean Chemical Society, vol. 59, no. 2, pp. 142-147, 2015.

[150] S. Sathiyanarayanan, S. K. Dhawan, D. C. Trivedi, and K. Balakrishnan, "Soluble conducting poly ethoxy aniline as an inhibitor for iron in $\mathrm{HCl}$," Corrosion Science, vol. 33, no. 12, pp. 1831-1841, 1992. 
[151] S. Sathiyanarayanan, K. Balakrishnan, S. K. Dhawan, and D. C. Trivedi, "Prevention of corrosion of iron in acidic media using poly (o-methoxy-aniline)," Electrochimica Acta, vol. 39, no. 6, pp. 831-837, 1994.

[152] R. Manickavasagam, K. Jeya Karthik, M. Paramasivam, and S. Venkatakrishna Iyer, "Poly(styrene sulphonic acid)-doped polyaniline as an inhibitor for the corrosion of mild steel in hydrochloric acid," Anti-Corrosion Methods and Materials, vol. 49, no. 1, pp. 19-26, 2002.

[153] M. M. Daouadji and N. Chelali, "Influence of molecular weight of poly (ortho-ethoxyaniline) on the corrosion inhibition efficiency of mild steel in acidic media," Journal of Applied Polymer Science, vol. 91, no. 2, pp. 1275-1284, 2004.

[154] S. K. Shukla, M. A. Quraishi, and R. Prakash, "A self-doped conducting polymer "polyanthranilic acid": An efficient corrosion inhibitor for mild steel in acidic solution," Corrosion Science, vol. 50, no. 10, pp. 2867-2872, 2008.

[155] S. Prakash, C. R. K. Rao, and M. Vijayan, "New polyaniline(PAni)-polyelectrolyte (PDDMAC) composites: synthesis and applications," Electrochimica Acta, vol. 53, no. 18, pp. 57045710, 2008.

[156] H. Bhandari, S. Sathiyanaranayan, V. Choudhary, and S. K. Dhawan, "Synthesis and characterization of proccessible polyaniline derivatives for corrosion inhibition," Journal of Applied Polymer Science, vol. 111, no. 5, pp. 2328-2339, 2009.

[157] H. Bhandari, V. Choudhary, and S. K. Dhawan, "Synergistic effect of copolymers composition on the electrochemical, thermal, and electrical behavior of 5-lithiosulphoisophthalic acid doped poly(aniline-co-2-isopropylaniline): synthesis, characterization, and applications," Polymers for Advanced Technologies, vol. 20, no. 12, pp. 1024-1034, 2009.

[158] M. A. Quraishi and S. K. Shukla, "Poly(aniline-formaldehyde): a new and effective corrosion inhibitor for mild steel in hydrochloric acid," Materials Chemistry and Physics, vol. 113, no. 2-3, pp. 685-689, 2009.

[159] R. Karthikaiselvi and S. Subhashini, "Study of adsorption properties and inhibition of mild steel corrosion in hydrochloric acid media by water soluble composite poly (vinyl alcohol-omethoxy aniline)," Journal of the Association of Arab Universities for Basic and Applied Sciences, vol. 16, no. 1, pp. 74-82, 2014.

[160] S. K. Shukla and M. A. Quraishi, "Effect of some substituted anilines-formaldehyde polymers on mild steel corrosion in hydrochloric acid medium," Journal of Applied Polymer Science, vol. 124, no. 6, pp. 5130-5137, 2011.

[161] Y. Yi, G. Liu, Z. Jin, and D. Feng, "The use of conducting polyaniline as corrosion inhibitor for mild steel in hydrochloric acid," International Journal of Electrochemical Science, vol. 8, pp. 3540-3550, 2013.

[162] J. A. Syed, S. Tang, H. Lu, and X. Meng, "Water-soluble polyaniline-polyacrylic acid composites as efficient corrosion inhibitors for 316SS," Industrial and Engineering Chemistry Research, vol. 54, no. 11, pp. 2950-2959, 2015.

[163] M. Rashid, S. Sabir, A. A. Rahim, and U. Waware, "Polyaniline/palm oil blend for anticorrosion of mild steel in saline environment," Journal of Applied Chemistry, vol. 2014, Article ID 973653, 6 pages, 2014.

[164] M. Rashid, S. Sabir, U. Waware, and A. A. Rahim, "Electropolymerization of poly(aniline-co- $p$-toluidine) on copper and its application as a corrosion inhibitor," Anti-Corrosion Methods and Materials, vol. 61, no. 5, pp. 334-342, 2014.
[165] S. Shi, Z. Zhang, and L. Yu, "Hydrophobic polyaniline/modified $\mathrm{SiO}_{2}$ coatings for anticorrosion protection," Synthetic Metals, vol. 233, pp. 94-100, 2017.

[166] Y. Jafari, S. M. Ghoreishi, and M. Shabani-Nooshabadi, "Electrochemical deposition and characterization of polyaniline-graphene nanocomposite films and its corrosion protection properties," Journal of Polymer Research, vol. 23, no. 5, pp. 91-104, 2016.

[167] Y. Zhao, Z. Zhang, L. Yu, and Q. Tang, "Electrospinning of polyaniline microfibers for anticorrosion coatings: an avenue of enhancing anticorrosion behaviors," SyntheticMetals, vol. 212, pp. 84-90, 2016.

[168] P. Sambyal, G. Ruhi, R. Dhawan, and S. K. Dhawan, "Designing of smart coatings of conducting polymer poly(aniline-cophenetidine) $/ \mathrm{SiO}_{2}$ composites for corrosion protection in marine environment," Surface and Coatings Technology, vol. 303, pp. 362-371, 2016.

[169] R. Alam, M. Mobin, and J. Aslam, "Investigation of anti-corrosive properties of poly(aniline-co-2-pyridylamineco-2,3-xylidine) and its nanocomposite poly(aniline-co-2pyridylamine- co-2,3-xylidine)/ZnO on mild steel in $0.1 \mathrm{M}$ HCl," Applied Surface Science, vol. 368, pp. 360-367, 2016.

[170] A. P. Srikanth, V. Raman, S. Tamilselvi, S. Nanjundan, and N. Rajendran, "Electropolymerization and corrosion protection of polyaniline and its copolymer on carbon steel," Anti-Corrosion Methods and Materials, vol. 55, no. 1, pp. 3-9, 2008.

[171] G. A. Phalak, D. M. Patil, and S. T. Mhaske, "Synthesis and characterization of thermally curable guaiacol based poly(benzoxazine-urethane) coating for corrosion protection on mild steel," European Polymer Journal, vol. 88, pp. 93-108, 2017.

[172] M. H. Heydari, H. Zebhi, K. Farhadi, and P. N. Moghadam, "Electrochemical synthesis of nanostructure poly(3-aminobenzoic acid), polyaniline and their bilayers on 430SS and their corrosion protection performances," Synthetic Metals, vol. 220, pp. 78-85, 2016.

[173] C. He, Z. Tian, B. Zhang et al., "Inhibition effect of environment-friendly inhibitors on the corrosion of carbon steel in recirculating cooling water," Industrial and Engineering Chemistry Research, vol. 54, no. 7, pp. 1971-1981, 2015.

[174] D. Thirumoolan, V. A. Katkar, G. Gunasekaran, T. Kanai, and K. Anver Basha, "Hyperbranched poly(cyanurateamine): a new corrosion inhibitor for mild steel in hydrochloric acid medium," Progress in Organic Coatings, vol. 77, no. 8, pp. 1253-1263, 2014.

[175] R. Solmaz, "Electrochemical synthesis of poly-2aminothiazole on mild steel and its corrosion inhibition performance," Progress in Organic Coatings, vol. 70, no. 2-3, pp. 122-126, 2011. 